Research Article

\title{
Nonlinear Responses of a Rotor-Bearing-Seal System with Pedestal Looseness
}

\author{
Junzhe Lin ${ }^{(D)}{ }^{1,2}$ Yulai Zhao, ${ }^{1}$ Pengfei Wang, ${ }^{1}$ Yuanyuan Wang, ${ }^{1}$ Qingkai Han, ${ }^{1,2}$ \\ and Hui Ma iD ${ }^{1,2}$ \\ ${ }^{1}$ School of Mechanical Engineering and Automation, Northeastern University, Shenyang, Liaoning 110819, China \\ ${ }^{2}$ Key Laboratory of Vibration and Control of Aero-Propulsion System Ministry of Education, Northeastern University, Shenyang, \\ Liaoning 110819, China \\ Correspondence should be addressed to Hui Ma; huima@me.neu.edu.cn
}

Received 11 March 2021; Revised 16 July 2021; Accepted 18 August 2021; Published 2 September 2021

Academic Editor: Said Elias

Copyright (c) 2021 Junzhe Lin et al. This is an open access article distributed under the Creative Commons Attribution License, which permits unrestricted use, distribution, and reproduction in any medium, provided the original work is properly cited.

In this paper, a pedestal looseness fault model of a rotor-bearing-seal system is established. Under two working conditions of the same direction eccentricity (Working Condition 1) and reverse eccentricity (Working Condition 2), rotor orbits, vibration waveforms, spectrum cascade, and Poincaré maps are used to study the dynamic characteristics of the system when the sliding bearing support is loosened. The influence of speed, the unbalance of two discs, the looseness clearance, and the mass of bearing support on system characteristics are analyzed. The study found that Working Condition 2 is more likely to cause looseness of the bearing support. Moreover, for the rotor system in this paper, the pedestal looseness fault is more likely to occur near the secondorder critical speed. Through analysis of the spectrum, it is found that the spectrum of the looseness fault will show multiple frequencies or continuous spectra, and the rotor orbits will appear "cylindrical."

\section{Introduction}

In the actual working process of rotating machinery, looseness is a common fault, which usually includes the looseness of rotating parts and the looseness of the foundation. The looseness between bearing support and foundation is the most common fault in rotating machinery. Looseness fault may be caused by long-term severe vibration of the system due to low installation quality and faults such as oil-film instability. Once a looseness fault occurs, it is likely to cause a serious rub impact fault between the rotor and stator. As the rub impact continues to become severe, the loose end may be completely separated from the foundation, resulting in machine crashes and deaths [1-4]. Therefore, the research on the looseness fault of rotating machinery is of great practical significance.

In the research of rotor system looseness fault, Chu and Tang [5] proposed a nonlinear mathematical model that considers the looseness of the rotor support. The periodic solution of the model was obtained by the shooting method, and its stability was analyzed by Floquet theory. Qin et al. [6] used the nonlinear finite element (FE) simulations method to calculate the time-varying stiffness caused by bolt looseness and introduced the calculated time-varying stiffness into the rotor's differential equation of motion, combined with the harmonic balance method to analyze the steady-state response of the system. Research on the nonlinear dynamics of the rotor system with coupled fault involving looseness has also attracted more and more attention [7, 8]. Muszynska and Goldman [9] first analyzed the nonlinear dynamics of the rotor system considering the coupled faults of rub impact and looseness. Zhang et al. [10] proposed the wavelet energy entropy method to identify the connection tightness of bolts in the rotor system, and the results showed that the index monotonously increases when the bolt assembly tightness decreases. Jiang et al. [11] studied rotor loosening models considering piecewise linear stiffness, damping force, and nonlinear elastic force; established corresponding mathematical model; and evaluated different degrees of looseness using the nonlinearity-measure-based assessment method. Wei et al. [12] proposed a novel contact 
model of rotating part looseness that considers bilinear stiffness based on the new characteristics of the rotor rotating part looseness found in experimental tests. Yang et al. [13] used the Lagrangian method to numerically study the coupling faults in the rotor system caused by imbalance, loosening support, and rub impact of rotating and static parts. Yang et al. [14] also studied the coupling faults caused by the loosening of the support and the rub impact based on a dual-rotor test rig, analyzed the vibration of the system at different speeds, established the corresponding mathematical model, and carried out numerical analysis. Yang et al. [15] further studied the rubbing-looseness coupling fault in a rotor system considering geometrical nonlinearity. In addition, many scholars studied the rotor-bearing system with looseness fault and achieved rich research results [16-20].

In recent years, there are an increasing number of scholars who pay attention to the nonlinear vibration of the seal-bearingrotor system because of its strong nonlinear characteristics, including oil-film instability and other coupling faults, such as the airflow-induced vibration [21-32]. For example, Wang et al. [21] studied the effect of the real high-pressure methane gas properties on the nonlinear behavior of the seal-rotor system. It is found that when the real gas properties are considered, the axis trajectory of the rotor will increase. Based on the Muszynska nonlinear seal force model, Li et al. [22] studied the stability of the seal-rotor system with rigid support and sliding bearing support, respectively. Ma et al. [23] analyzed the influence of some sealing parameters such as length and diameter on system dynamics. Zhang et al. [24] researched the dynamic characteristics of the rotor-journal bearing system and considered the flow field features of the seal. Ma et al. [26] analyzed the effect of seal force on oil-film instability. Li et al. [27] proposed a new nonlinear model of rotor-bearing-seal system based on the Hamilton principle. It is found that, with the increase of the rotating speed, the system exhibits periodic, double-periodic, multiperiodic, quasiperiodic, and chaotic motion. Under the combined action of air force and oil-film force, the system vibration will become more serious. Luo et al. [29] established the finite element model of seal-ball bearing-rotor test bench and discussed the influence of the rubbing fault inside the seal on system dynamic behavior. In addition, based on the lumped mass method and the principle of displacement equilibrium of the rotor system, Zhou et al. [30] proposed a coupled lateraltorsional dynamic model describing the gear-rotor-seal-bearing (GRSB) system of high-speed centrifugal pumps, and then they analyzed the effects of transmission ratio on the system vibration response.

According to the existing literature, many scholars have studied the nonlinear vibration problem of rotor-bearing pedestal looseness and achieved fruitful results. However, the seal-bearing-rotor system is a strong nonlinear system because of the airflow force of the seal and the oil-film force of the bearing. In particular, both the oil-film instability and airflow-induced vibration are self-excited vibrations caused by fluids. Once they occur, the stable operation of the system will be damaged seriously, the vibration of the rotor system will be aggravated, and secondary faults of the rotor system will be further caused, such as loosening, cracking, and rubbing. However, there are few studies on the dynamics of rotor system with fault under twofluid excitation. Based on this practical background, this paper aims to theoretically reveal the vibration characteristics and influence rules of rotor system with loosening fault under the action of two fluids and to provide a certain basis for fault diagnosis and identification of this kind of rotating machinery.

In this paper, a nonlinear dynamic model of the rotorbearing-seal system considering the sliding bearing, labyrinth seal, and support looseness is first established. The lumped mass method is used to study the system under two working conditions: the in-phase unbalance and out-ofphase unbalance of two discs. The influence of the looseness fault of the right bearing support on the nonlinear dynamic characteristics of the system and the influence of unbalanced mass, loose clearance, and mass of the right bearing support on the system response are determined.

\section{Mathematical Model of a Rotor-Bearing-Seal- Foundation System with Pedestal Looseness}

A rotor-bearing-seal-foundation system model with oneend (right end) looseness is established in this paper, as shown in Figure 1.

It can be shown in Figure 1 that the left bearing is a selflubricating graphite bearing, which is simulated by springdamping, and the right bearing is a sliding bearing, and the oil-film force adopts the Capone short bearing oil-film force model [33]. The sealing force adopts the Muszynska model $[34,35]$. According to $[26,36]$, the governing equation of a rotor-bearing-seal system is

$$
\mathbf{M} \ddot{\mathbf{q}}+(\mathbf{G}+\mathbf{C}) \dot{\mathbf{q}}+\mathbf{K q}=\mathbf{F}_{e}+\mathbf{F}_{s}+\mathbf{F}_{b}-\mathbf{F}_{g},
$$

where $\mathbf{M}$ is the mass matrix, $\mathbf{G}$ is the gyroscopic matrix, $\mathbf{C}$ is the damping matrix (including the left bearing damping), $\mathbf{K}$ is the stiffness matrix (including the left bearing stiffness), $\mathbf{q}$ is the displacement vector, and $\mathbf{F}_{\mathrm{e}}, \mathbf{F}_{\mathrm{s}}, \mathbf{F}_{\mathrm{b}}$, and $\mathbf{F}_{\mathrm{g}}$ are unbalanced force vector, nonlinear sealing force vector, oil-film force vector, and external excitation vector of gravity, respectively.

$$
\begin{aligned}
& \mathbf{M}=\left[\begin{array}{cc}
\mathbf{M}_{x} & 0 \\
0 & \mathbf{M}_{y}
\end{array}\right], \quad \mathbf{M}_{x}=\mathbf{M}_{y}=\operatorname{diag}\left[m_{1}, J_{d 1}, m_{2}, J_{d 2}, m_{3}, J_{d 3}, m_{4}, J_{d 4}, m_{5}, J_{d 5}\right], \\
& \mathbf{G}=\omega \mathbf{J}=\omega\left[\begin{array}{cc}
0 & \mathbf{J}_{1} \\
-\mathbf{J}_{1}^{T} & 0
\end{array}\right], \quad \mathbf{J}_{1}=\operatorname{diag}\left[0, J_{p 1}, 0, J_{p 2}, 0, J_{p 3}, 0, J_{p 4}, 0, J_{p 5}\right],
\end{aligned}
$$




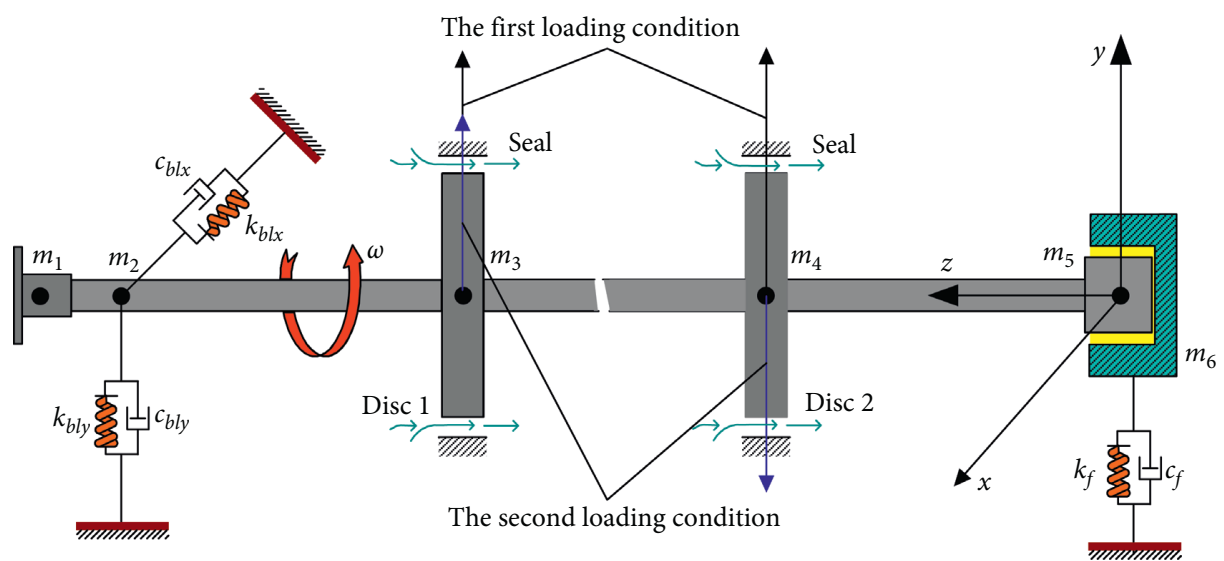

Figure 1: Mechanical model of the rotor-bearing-seal-foundation system.

in which $\omega$ is the rotating speed of the rotor.

In equations (2) and (3), $m_{i}, J_{\mathrm{pi}}$, and $J_{\mathrm{di}}(i=1,2,3,4,5)$ are lumped mass, polar moment of inertia of lumped mass points, and diametral moment of inertia of lumped mass points, respectively. $i$ is the number of lumped mass points.

$$
\begin{aligned}
\mathbf{K} & =\left[\begin{array}{cc}
\mathbf{K}_{x} & 0 \\
0 & \mathbf{K}_{y}
\end{array}\right], \\
\mathbf{K}_{x} & =\left[\begin{array}{ccccccccccc}
k_{11} & k_{12} & k_{13} & k_{14} & 0 & 0 & 0 & 0 & 0 & 0 \\
k_{12} & k_{22} & k_{23} & k_{24} & 0 & 0 & 0 & 0 & 0 & 0 \\
k_{13} & k_{23} & k_{33}+k_{b l x} & k_{34} & k_{35} & k_{36} & 0 & 0 & 0 & 0 \\
k_{14} & k_{24} & k_{34} & k_{44} & k_{45} & k_{46} & 0 & 0 & 0 & 0 \\
0 & 0 & k_{35} & k_{45} & k_{55} & k_{56} & k_{57} & k_{58} & 0 & 0 \\
0 & 0 & k_{36} & k_{46} & k_{56} & k_{66} & k_{67} & k_{68} & 0 & 0 \\
0 & 0 & 0 & 0 & k_{57} & k_{67} & k_{77} & k_{78} & k_{79} & k_{7,10} \\
0 & 0 & 0 & 0 & k_{58} & k_{68} & k_{78} & k_{88} & k_{89} & k_{8,10} \\
0 & 0 & 0 & 0 & 0 & 0 & k_{79} & k_{89} & k_{99} & k_{9,10} \\
0 & 0 & 0 & 0 & 0 & 0 & k_{7,10} & k_{8,10} & k_{9,10} & k_{10,10}
\end{array}\right], \\
\mathbf{K}_{y} & =\left[\begin{array}{ccccccccccccc}
11 & -k_{12} & k_{13} & -k_{14} & 0 & 0 & 0 & 0 & 0 & 0 \\
-k_{12} & k_{22} & -k_{23} & k_{24} & 0 & 0 & 0 & 0 & 0 & 0 \\
k_{13} & -k_{23} & k_{33}+k_{b l y} & -k_{34} & k_{35} & -k_{36} & 0 & 0 & 0 & 0 \\
-k_{14} & k_{24} & -k_{34} & k_{44} & -k_{45} & k_{46} & 0 & 0 & 0 & 0 \\
0 & 0 & k_{35} & -k_{45} & k_{55} & -k_{56} & k_{57} & -k_{58} & 0 & 0 \\
0 & 0 & -k_{36} & k_{46} & -k_{56} & k_{66} & -k_{67} & k_{68} & 0 & 0 \\
0 & 0 & 0 & 0 & k_{57} & -k_{67} & k_{77} & -k_{78} & k_{79} & -k_{7,10} \\
0 & 0 & 0 & 0 & -k_{58} & k_{68} & -k_{78} & k_{88} & -k_{89} & k_{8,10} \\
0 & 0 & 0 & 0 & 0 & 0 & k_{79} & -k_{89} & k_{99} & -k_{9,10} \\
0 & 0 & 0 & 0 & 0 & 0 & -k_{7,10} & k_{8,10} & -k_{9,10} & k_{10,10}
\end{array}\right],
\end{aligned}
$$

where $k_{\mathrm{blx}}$ and $k_{\mathrm{bly}}$ represent the stiffnesses of the left bearing in $x$ and $y$ directions, respectively. The matrix elements of $\mathbf{K}_{x}$ and $\mathbf{K}_{y}$ are as shown as follows: 


$$
\begin{aligned}
& \left\{\begin{array}{l}
k_{11}=a_{11} \\
k_{12}=a_{21} \\
k_{13}=-a_{11} \\
k_{14}=a_{21}
\end{array},\right. \\
& \left\{\begin{array}{l}
k_{22}=l_{1} a_{21}-a_{31} \\
k_{23}=-a_{21} \\
k_{24}=a_{31}
\end{array},\right. \\
& \left\{\begin{array}{l}
k_{33}=a_{11}+a_{12} \\
k_{34}=-a_{21}+a_{22} \\
k_{35}=-a_{12} \\
k_{36}=a_{22}
\end{array},\right. \\
& \left\{\begin{array}{l}
k_{44}=l_{1} a_{21}-a_{31}+l_{2} a_{22}-a_{32} \\
k_{45}=-a_{22} \\
k_{46}=a_{32}
\end{array},\right. \\
& \left\{\begin{array}{l}
k_{55}=a_{12}+a_{13} \\
k_{56}=-a_{22}+a_{23} \\
k_{57}=-a_{13} \\
k_{58}=a_{23}
\end{array},\right. \\
& \left\{\begin{array}{l}
k_{66}=l_{2} a_{22}-a_{32}+l_{3} a_{23}-a_{33} \\
k_{67}=-a_{23} \\
k_{68}=a_{33}
\end{array},\right. \\
& \left\{\begin{array}{l}
k_{77}=a_{13}+a_{14} \\
k_{78}=-a_{23}+a_{24} \\
k_{79}=-a_{14} \\
k_{7,10}=a_{24}
\end{array},\right. \\
& \left\{\begin{array}{l}
k_{88}=l_{3} a_{23}-a_{33}+l_{4} a_{44}-a_{34} \\
k_{89}=-a_{24} \\
k_{8,10}=a_{34}
\end{array},\right. \\
& \left\{\begin{array}{l}
k_{99}=a_{14} \\
k_{9,10}=-a_{24} \\
k_{10,10}=l_{4} a_{24}-a_{34}
\end{array},\right.
\end{aligned}
$$

in which $a_{1 i}=12 E I / l_{i}^{3}, a_{2 i}=(1 / 2) l_{i} a_{1 i}$, and $a_{3 i}=(1 / 6) l_{i}^{2} a_{1 i}$. The subscript $i$ represents $1,2,3$, and 4 , respectively. $l_{i}$ is the distance between every two adjacent lumped mass points; $E$ is Young's modulus of elasticity; $E=2.1 \times 10^{11} \mathrm{~Pa}$. $I$ is the area moment of inertia.

$$
\begin{aligned}
\mathbf{q}= & {\left[x_{1}, \theta_{y 1}, x_{2}, \theta_{y 2}, x_{3}, \theta_{y 3}, x_{4}, \theta_{y 4}, x_{5}, \theta_{y 5}, y_{1},\right.} \\
& \left.\cdot \theta_{x 1}, y_{2}, \theta_{x 2}, y_{3}, \theta_{x 3}, y_{4}, \theta_{x 4}, y_{5}, \theta_{x 5}\right]^{T},
\end{aligned}
$$

where $x_{i}, y_{i}, \theta_{x i}, \theta_{y i}(i=1,2,3,4,5)$ are displacements in $x$ and $y$ directions and angles of orientation associated with the $x$ and $y$ axes, respectively.

$$
\mathrm{C}=\mathrm{C}_{1}+\mathrm{C}_{2},
$$

in which $\mathbf{C}_{1}$ is the rotor damping matrix and $\mathbf{C}_{2}$ is the bearing damping matrix. For the rotor studied in this paper, the manufacturing material is single, and the properties of the material can be regarded as isotropic. Then the damping characteristics of the system are distributed evenly. Therefore, the proportional damping is used to simulate the rotor damping $\mathbf{C}_{1}$. The Rayleigh damping model, as a kind of proportional damping model, is widely used in engineering practice. The mathematical expression is written as follows:

$$
\mathbf{C}_{1}=\alpha \mathbf{M}+\beta \mathbf{K}
$$

where $\alpha$ and $\beta$ are the Rayleigh damping coefficients, and their values can be determined experimentally. According to the basic theory of vibration, equation (8) is transformed into modal coordinates, and the damping matrix $\mathbf{C}_{N}$ in canonical coordinate is a diagonal matrix, which can be expressed as [37]

$$
\mathbf{C}_{N}=\operatorname{diag}\left(\alpha+\beta \omega_{1}^{2}, \ldots \ldots \alpha+\beta \omega_{j}^{2}, \ldots \ldots \alpha+\beta \omega_{20}^{2}\right) .
$$

In (9), $\omega_{j}$ represents the $j$-th natural frequency. If the first and second natural frequencies $\omega_{1}$ and $\omega_{2}(\mathrm{rev} / \mathrm{min})$ of the system are known, then $\alpha+\beta \omega_{1}{ }^{2}=2 \xi_{1} \omega_{1}, \alpha+\beta \omega_{2}{ }^{2}=2 \xi_{2} \omega_{2}$. Therefore, the first and second modal damping ratios $\xi_{1}$ and $\xi_{2}$ can be expressed as follows, respectively:

$$
\left\{\begin{array}{l}
\xi_{1}=\frac{1}{2}\left(\frac{\alpha}{\omega_{1}}+\beta \omega_{1}\right), \\
\xi_{2}=\frac{1}{2}\left(\frac{\alpha}{\omega_{2}}+\beta \omega_{2}\right) .
\end{array}\right.
$$

The damping coefficients $a$ and $\beta$ can be obtained by solving the binary linear equations in (10). The formula is expressed as follows: 


$$
\begin{aligned}
& \left\{\begin{array}{l}
\alpha=2 \frac{\left(\left(\xi_{2} / \omega_{2}\right)-\left(\xi_{1} / \omega_{1}\right)\right)}{\left(\left(1 / \omega_{2}^{2}\right)-\left(1 / \omega_{1}^{2}\right)\right)}, \\
\beta=2 \frac{\left(\xi_{2} \omega_{2}-\xi_{1} \omega_{1}\right)}{\left(\omega_{2}^{2}-\omega_{1}^{2}\right)},
\end{array}\right. \\
& \mathbf{C}_{2}=\operatorname{diag}\left[0,0, c_{b l x}, 0,0,0,0,0,0,0,0,0, c_{b l y}, 0,0,0,0,0,0,0\right] \text {, } \\
& \omega^{2} \mathbf{M} \ddot{\tilde{\mathbf{q}}}+\omega(\mathbf{G}+\mathbf{C}) \dot{\tilde{\mathbf{q}}}+\mathbf{K} \widetilde{\mathbf{q}}=\frac{\mathbf{F}_{e}+\mathbf{F}_{s}+\mathbf{F}_{b}-\mathbf{F}_{g}}{c},
\end{aligned}
$$

where $c_{b l x}$ and $c_{b l y}$ are the dampings of the left bearing in $x$ and $y$ directions, respectively.

For the convenience of calculation, the dimensionless transformations are defined as $\Delta=\omega t$ and $\widetilde{\mathbf{q}}=\mathbf{q} / c$.

Equation (1) can be rewritten as a dimensionless form

$$
\mathbf{F}_{e}=\left[\begin{array}{c}
0,0,0,0, m_{3} e_{1} \omega^{2} \cos \left(\Delta+\phi_{1}\right), 0, m_{4} e_{2} \omega^{2} \cos \left(\Delta+\phi_{2}\right), 0,0,0,0,0,0,0, \\
m_{3} e_{1} \omega^{2} \sin \left(\Delta+\phi_{1}\right) 0, m_{4} e_{2} \omega^{2} \sin \left(\Delta+\phi_{2}\right), 0,0,0
\end{array}\right]^{T},
$$

where $m_{3} e_{1}$ and $m_{4} e_{2}$ denote eccentricity of unbalance mass of the left and right discs. $\varphi_{1}$ and $\varphi_{2}$ represent initial phase angles of eccentricity in left and right discs.

$$
\mathbf{F}_{b}=\left[0,0,0,0,0,0,0,0, F_{b x}, 0,0,0,0,0,0,0,0,0, F_{b y}, 0\right]^{T},
$$

where $F_{b x}$ and $F_{b y}$ represent nonlinear oil-film forces of the right bearing in $x$ and $y$ directions, respectively. The Capone oil-film force model is used in this study. The equations are as follows [33]:

$$
\begin{aligned}
& {\left[\begin{array}{l}
F_{b x} \\
F_{b y}
\end{array}\right]=\sigma\left[\begin{array}{l}
f_{b x} \\
f_{b y}
\end{array}\right],} \\
& {\left[\begin{array}{l}
f_{b x} \\
f_{b y}
\end{array}\right]=\frac{\left[(\tilde{x}-2 \dot{\tilde{y}})^{2}+(\tilde{y}+2 \dot{\tilde{x}})^{2}\right]^{1 / 2}}{1-\tilde{x}^{2}-\tilde{y}^{2}} \times\left[\begin{array}{l}
3 \tilde{x} V(\tilde{x}, \tilde{y}, \alpha)-\sin \alpha G(\tilde{x}, \tilde{y}, \alpha)-2 \cos \alpha S(\tilde{x}, \tilde{y}, \alpha) \\
3 \tilde{y} V(\tilde{x}, \tilde{y}, \alpha)+\cos \alpha G(\tilde{x}, \tilde{y}, \alpha)-2 \sin \alpha S(\tilde{x}, \tilde{y}, \alpha)
\end{array}\right],}
\end{aligned}
$$

where

$$
\begin{aligned}
V(\tilde{x}, \tilde{y}, \alpha) & =\frac{2+(\tilde{y} \cos \alpha-\tilde{x} \sin \alpha) G(\tilde{x}, \tilde{y}, \alpha)}{1-\tilde{x}^{2}-\tilde{y}^{2}}, \\
S(\tilde{x}, \tilde{y}, \alpha) & =\frac{\tilde{x} \cos \alpha+\tilde{y} \sin \alpha}{1-(\tilde{x} \cos \alpha+\tilde{y} \sin \alpha)^{2}}, \\
G(\tilde{x}, \tilde{y}, \alpha) & =\frac{2}{\left(1-\tilde{x}^{2}-\tilde{y}^{2}\right)^{1 / 2}}\left[\frac{\pi}{2}+\arctan \frac{\tilde{y} \cos \alpha-\tilde{x} \sin \alpha}{\left.\left(1-\tilde{x}^{2}-\tilde{y}^{2}\right)^{1 / 2}\right],}\right. \\
\alpha & =\arctan \left(\frac{\tilde{y}+2 \dot{\tilde{x}}}{\tilde{x}-2 \dot{\tilde{y}}}\right)-\frac{\pi}{2} \operatorname{sign}\left(\frac{\tilde{y}+2 \dot{\tilde{x}}}{\tilde{x}-2 \dot{\tilde{y}}}\right)-\frac{\pi}{2} \operatorname{sign}(\tilde{y}+2 \dot{\tilde{x}}),
\end{aligned}
$$


where $\sigma=\eta \omega(D / 2) L(D / 2 c)^{2}(L / D)^{2}$ is Sommerfeld coefficient. $\eta, L, D$, and $c$ denote lubricant viscosity, bearing length, bearing diameter, and bearing radial clearance, respectively.
In (12), the expressions of gravity vector and seal force vector are as follows:

$$
\begin{aligned}
\mathbf{F}_{g} & =\left[0,0,0,0,0,0,0,0,0,0, m_{1} g, 0, m_{2} g, 0, m_{3} g, 0, m_{4} g, 0, m_{5} g, 0\right]^{T}, \\
\mathbf{F}_{s} & =\left[0,0,0,0, F_{f 1 x}, 0, F_{f 2 x}, 0,0,0,0,0,0,0, F_{f 1 y}, 0, F_{f 2 y}, 0,0,0\right]^{T}
\end{aligned}
$$

where $g$ is the gravity acceleration, which is equal to $9.8 \mathrm{~m} / \mathrm{s}^{2}$. $F_{f 1 x}, F_{f 1 y}, F_{f 2 x}$ and $F_{f 1 y}$ are the components of sealing force in $x$ and $y$ directions on nodes 3 and 4, respectively.

The Muszynska seal force model [35] is adopted in this study because it is based on a large number of experiments and has a clear physical meaning, which can better reflect the nonlinear characteristics of the seal force. Furthermore, its accuracy has been generally recognized and validated in practical applications. The circumferential angular velocity of fluid near the rotor is $\omega$, and that near the stator is reduced to zero. Further, $t$ is introduced to express the circumferential average velocity ratio of fluid, and $\tau \omega$ represents the average flow velocity in the seal cavity. The specific expression of the seal force is as follows:

$$
\left\{\begin{array}{c}
F_{f x} \\
F_{f y}
\end{array}\right\}=-\left[\begin{array}{cc}
K_{f}-m_{f} \tau^{2} \omega^{2} & \tau \omega D_{f} \\
-\tau \omega D_{f} & K_{f}-m_{f} \tau^{2} \omega^{2}
\end{array}\right]\left\{\begin{array}{l}
x \\
y
\end{array}\right\}-\left[\begin{array}{cc}
D_{f} & 2 \tau \omega m_{f} \\
-2 \tau \omega m_{f} & D_{f}
\end{array}\right]\left\{\begin{array}{l}
\dot{x} \\
\dot{y}
\end{array}\right\}-\left[\begin{array}{cc}
m_{f} & 0 \\
0 & m_{f}
\end{array}\right]\left\{\begin{array}{l}
\ddot{x} \\
\ddot{y}
\end{array}\right\} .
$$

In (18), $K_{f}, D_{f}$, and $m_{f}$ represent the equivalent stiffness, equivalent damping, and equivalent mass, respectively. Here, $K_{f}, D_{f}$, and $t$ are the nonlinear functions related to the disturbance displacements $x$ and $y$, which can be expressed as follows:

$$
\begin{aligned}
K_{f} & =K_{0}\left(1-e^{2}\right)^{-n_{f}}, \\
D_{f} & =D_{0}\left(1-e^{2}\right)^{-n_{f}}, \quad 0.5<n_{f}<3, \\
\tau_{f} & =\tau_{0}\left(1-e^{2}\right)^{b}, \quad 0<b_{0}<1, \\
e & =\frac{\sqrt{x^{2}+y^{2}}}{c}, \tau_{0}<0.5 .
\end{aligned}
$$

In (19), the parameters $n_{f}, b_{0}$, and $\tau_{0}$ describe the specific seal structure, and $e$ and $c$ represent the relative eccentricity of the rotor and the seal clearance, respectively. Furthermore, $K_{0}, D_{0}$, and $m_{f}$ can be expressed as follows [38]:

$$
\begin{aligned}
& K_{0}=\mu_{0} \mu_{3}, \\
& D_{0}=\mu_{1} \mu_{3} T, \\
& m_{f}=\mu_{2} \mu_{3} T^{2} .
\end{aligned}
$$

The expressions of parameters presented in (20) are listed as follows:

$$
\begin{aligned}
& \mu_{0}=\frac{2 \sigma^{2}}{1+z+2 \sigma} E\left(l-m_{0}\right) \\
& \mu_{1}=\frac{2 \sigma^{2}}{1+z+2 \sigma}\left[\frac{E}{\sigma}+\frac{B}{2}\left(E+\frac{1}{6}\right)\right] \text {, } \\
& \mu_{2}=\frac{\sigma(E+(1 / 6))}{1+z+2 \sigma}, \\
& \mu_{3}=\frac{\pi R \Delta P}{\lambda} \text {, } \\
& T=\frac{l}{v_{a}}, \\
& \sigma=\frac{\lambda l}{c} \\
& \lambda=n_{0} R_{a}^{m_{0}}\left[1+\left(\frac{R_{v}}{R_{a}}\right)^{2}\right]^{\left(1+m_{0}\right) / 2}, \\
& E=\frac{1+z}{1+z+2 \sigma}, \\
& B=2-\frac{\left(R_{v} / R_{a}\right)^{2}-m_{0}}{\left(R_{v} / R_{a}\right)^{2}+1}, \\
& R_{v}=\frac{R c \omega}{\gamma} \\
& R_{a}=\frac{2 v_{a} c}{\gamma}
\end{aligned}
$$

Next, consider the looseness fault in the right bearing. The schematic of the connecting bolt looseness fault is shown in Figure 2. 


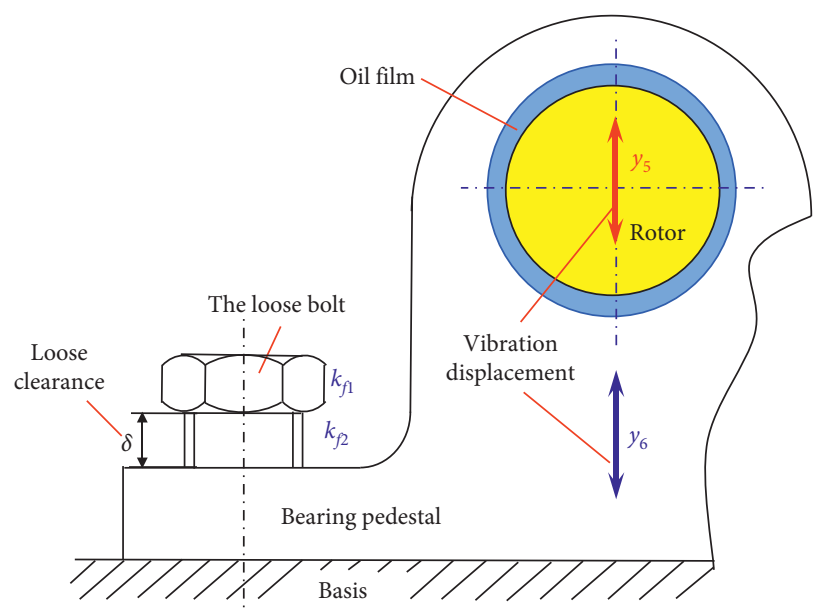

Figure 2: Schematic diagram of loose connecting bolt on bearing pedestal.

At this time, the governing (1) can be expressed as

$$
\overline{\mathbf{M}} \ddot{\overline{\mathbf{q}}}+(\overline{\mathbf{G}}+\overline{\mathbf{C}}) \dot{\overline{\mathbf{q}}}+\overline{\mathbf{K}} \overline{\mathbf{q}}=\overline{\mathbf{F}}_{e}+\overline{\mathbf{F}}_{s}+\overline{\mathbf{F}}_{b}-\overline{\mathbf{F}}_{g},
$$

where $\quad \overline{\mathbf{M}}=\left[\begin{array}{cc}\mathbf{M} & 0 \\ 0 & m_{6}\end{array}\right], \quad \overline{\mathbf{G}}=\left[\begin{array}{cc}\mathbf{G} & 0 \\ 0 & 0\end{array}\right], \quad \overline{\mathbf{C}}=\left[\begin{array}{cc}\mathbf{C} & 0 \\ 0 & c_{f}\end{array}\right]$, $\overline{\mathbf{K}}=\left[\begin{array}{cc}\mathbf{K} & 0 \\ 0 & k_{f}\end{array}\right], \quad \overline{\mathbf{q}}=\left[\mathbf{q}^{T}, y_{6}\right]^{T}, \overline{\mathbf{F}}_{e}=\left[\mathbf{F}_{e}^{T}, 0\right]^{T}, \quad \overline{\mathbf{F}}_{s}=\left[\mathbf{F}_{s}^{T}, 0\right]^{T}$, $\overline{\mathbf{F}}_{b}=\left[\mathbf{F}_{b}^{T},-F_{b y}\right]^{T}$, and $\overline{\mathbf{F}}_{g}=\left[\mathbf{F}_{g}^{T}, m_{6} g\right]^{T} \cdot y_{6}$ is the displacement of the bearing support in vertical direction. $k_{f}$ and $c_{f}$ are the equivalent stiffness and equivalent damping between the bearing support and the foundation, respectively, which behave as piecewise linear under different bearing displacement $y_{6}$. The expressions are as follows:

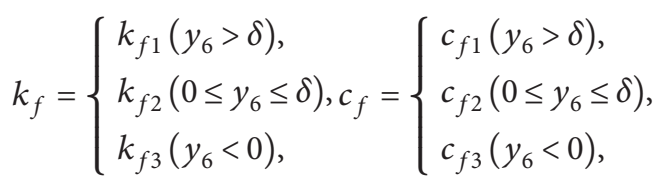

where $k_{f 1}$ is the tensile stiffness of the bolt, $k_{f 2}$ is the stiffness when the bolt is loosened, $k_{f 3}$ is the stiffness when the bolt is not loosened, and $\delta$ is the clearance between the bearing support and the foundation.

The simulation model parameters of the rotor and bearing are shown in Table 1.

The seal parameters related to the rotor-bearing-sealing system are shown in Table 2.

The Newmark- $\beta$ integral method is adopted to solve (23). The loosening fault occurs at the bearing support, the journal position changes more obviously, so the right end journal and bearing support are taken as research objects. Under two working conditions (Working Conditions 1 and 2 are the same direction eccentricity and reverse eccentricity, respectively), the influences of speed, unbalance mass, looseness clearance, and bearing support mass on the dynamic characteristics of the system are studied. Then the dynamic response is observed using the bifurcation diagrams, spectrum cascades, Poincaré maps, FFT spectra, vibration waveform, and rotor orbits. The Poincaré map is adopted to indicate the
TABLE 1: Model parameters of the rotor and the bearing.

\begin{tabular}{lc}
\hline Parameters & Values \\
\hline$m_{1}, m_{2}, m_{3}, m_{4}, m_{5}(\mathrm{~kg})$ & $0.0439,0.02343,0.5919,0.5919,0.09633$ \\
$J_{p 1}, J_{d 1}\left(\mathrm{~kg} \cdot \mathrm{m}^{2}\right)$ & $2.957 \times 10^{-6}, 3.196 \times 10^{-6}$ \\
$J_{p 2}, J_{d 2}\left(\mathrm{~kg} \cdot \mathrm{m}^{2}\right)$ & $0.2929 \times 10^{-6}, 2.966 \times 10^{-6}$ \\
$J_{p 3}, J_{d 3}\left(\mathrm{~kg} \cdot \mathrm{m}^{2}\right)$ & $4.735 \times 10^{-4}, 2.478 \times 10^{-4}$ \\
$J_{p 4}, J_{d 4}\left(\mathrm{~kg} \cdot \mathrm{m}^{2}\right)$ & $4.735 \times 10^{-4}, 2.478 \times 10^{-4}$ \\
$J_{p 5}, J_{d 5}\left(\mathrm{~kg} \cdot \mathrm{m}^{2}\right)$ & $7.526 \times 10^{-6}, 8.780 \times 10^{-6}$ \\
$\eta(\mathrm{Pa} \cdot \mathrm{s})$ & 0.04 \\
$k_{b l x}, k_{b l y}(\mathrm{~N} / \mathrm{m})$ & $2 \times 10^{8}, 2 \times 10^{8}$ \\
$c_{b l x}, c_{b l y}(\mathrm{~N} \cdot \mathrm{s} / \mathrm{m})$ & $2 \times 10^{3}, 2 \times 10^{3}$ \\
$\mathrm{C}, D, L(\mathrm{~mm})$ & $0.3,25,10$ \\
\hline
\end{tabular}

TABLE 2: Seal parameters.

\begin{tabular}{lc}
\hline Parameters & Values \\
\hline$v(\mathrm{~m} / \mathrm{s})$ & 10 \\
$\Delta P(\mathrm{~Pa})$ & $0.1 \times 10^{5}$ \\
$R_{f}(\mathrm{~mm})$ & 43 \\
$c_{f}(\mathrm{~mm})$ & 1.5 \\
$l_{f}(\mathrm{~mm})$ & 18 \\
\hline
\end{tabular}

nature of the system motion. It is a stroboscopic diagram of motion in a phase plane, which is composed of the time series at a constant interval of $T_{r}$. The rotation period of rotor $T_{r}=2 \pi / \omega$, where $\omega$ is the rotor speed $(\mathrm{rad} / \mathrm{s})$.

\section{Dynamic Response under Looseness}

According to the dynamic model established in this paper, the dynamic response of the looseness fault rotor system at different speeds under two working conditions is studied. The rotating frequency caused by the rotor unbalance is defined as $f_{n}$ and its value is one-sixtieth of the speed ( $\mathrm{r} / \mathrm{min})$. The first-order oil-film oscillation frequency of the sliding bearing is defined as $f_{n 1}$, and its value is about the first-order natural frequency of the system. The other parameters of the system are the unbalance of the two discs $m_{3} e_{1}=m_{4} e_{2}=1.1838 \times 10^{-4} \mathrm{~kg} \cdot \mathrm{m}$, the looseness clearance $\delta=1 \mathrm{~mm}$, the tensile stiffness of bolt $k_{f 1}=9 \times 10^{7} \mathrm{~N} / \mathrm{m}$, the stiffness of bolt when the bolt is loosened $k_{f 2}=0 \mathrm{~N} / \mathrm{m}$, the 
stiffness of the bolt when the bolt is not loosened $k_{f 3}=2 \times 10^{9} \mathrm{~N} /$ $\mathrm{m}$, and the mass of the bearing support $m_{6}=1.1 \mathrm{~kg}$.

3.1. In-Phase Unbalances of Two Discs. The spectrum cascade of the right journal (mass 5) in the vertical direction $(y$ direction) under Working Condition 1 is shown in Figure 3. When the rotating speed is $600 \leq \omega<6900 \mathrm{r} / \mathrm{min}$, the rotor response is synchronous positive precession. In addition, the frequency $f_{r}, 2 f_{r}$, and $3 f_{r}$ also appear. When the speed reaches $6900 \mathrm{r} / \mathrm{min}$, the first-order oil-film oscillation begins to be violent and reaches the instability speed. At the same time, the lock frequency of the first-order oil-film oscillation $\left(f_{n 1}\right)$ is about $32.2 \mathrm{~Hz}$.

Figures 4 and 5 are, respectively, the orbit, the Poincaré maps, and the vibration waveforms of the right journal at various speeds under Working Condition 1.

When $\omega=2800 \mathrm{r} / \mathrm{min}$, according to Figure 4, it can be seen that the orbit is an elliptic, and the Poincaré maps are an isolated point. According to Figure 5(a), it can be seen that the vibration waveforms show a sine curve under the unbalanced excitation. These characteristics all indicate that the system is in period 1 motion. In addition, according to the spectrum cascade in Figure 3, the first-order oil-film oscillation frequency $f_{n 1}$ does not appear. When $\omega=5000 \mathrm{r} /$ min, the orbit, Poincaré maps, and the vibration waveforms all show that the system is still operating stably. When $\omega=7500$ and $12000 \mathrm{r} / \mathrm{min}$, due to the occurrence of oil-film oscillation, there are many inner " 8 "s in the orbits. The Poincaré maps are closed loops, indicating a quasiperiodic motion.

3.2. Out-of-Phase Unbalances of Two Discs. In Working Condition 2, the spectrum cascade of the right journal (mass 5 ) in the vertical direction ( $y$-direction) is shown in Figure 6. When the speed is $6000 \leq \omega \leq 7200 \mathrm{r} / \mathrm{min}$, it can be clearly seen that, in addition to $f_{r}, 2 f_{r}, 3 f_{r}$, and other multipliers, $f_{r} / 3$, $f_{r} / 2,2 f_{r} / 3,4 f_{r} / 3,5 f_{r} / 3$, etc., also appear. This is because in this speed range, it is close to the second-order critical speed, and the vibration is more severe, which is more likely to cause the bearing support to loosen. In addition, when $\omega \geq 13800 \mathrm{r} /$ min, there exists a first-order oil-film oscillation in the system. At this time, the system still has a frequency lock phenomenon at around $32.2 \mathrm{~Hz}$, which is the same as Working Condition 1.

The rotor orbits and Poincaré maps of the right journal at various speeds under Working Condition 2 are shown in Figure 7. When the speed $\omega=5700 \mathrm{r} / \mathrm{min}, 6600 \mathrm{r} / \mathrm{min}$, and $6900 \mathrm{r} / \mathrm{min}$, which are close to the second-order critical speed of the system, and the looseness is obvious, so the orbits are "cylindrical," which is a typical orbit characteristic of looseness. At this time, it can be seen from Figure 7(b) that the Poincaré maps show that the system motions are chaotic.

Figures 8 and 9 show the vibration waveforms of the right journal and bearing support in the vertical direction $(y$ direction) under Working Condition 2. It can be seen from Figure 8 that when the speed $\omega=5700 \mathrm{r} / \mathrm{min}$ and $6900 \mathrm{r} / \mathrm{min}$, the amplitude of the vibration waveforms increases significantly due to the occurrence of looseness. It can be seen from Figure 9 that since the looseness clearance used in the simulation is large $(\delta=1 \mathrm{~mm})$, the support will not be restricted by the bolt due to the loosening gap, so the vibration waveforms only have single-sided clipping.

\section{The Influence of Loose Rotor System Parameters on the Dynamic}

For the rotor system studied in this paper, looseness fault is more likely to be caused under Working Condition 2. For this reason, this section only studies the influence of system parameters on the dynamic for Working Condition 2.

4.1. Influence of Unbalance. Taking the unbalance (disc eccentricity $e$ ) as the control parameter, other parameters of the system are as follows: the rotating speed $\omega=7100 \mathrm{r} / \mathrm{min}$, the looseness clearance $\delta=1 \mathrm{~mm}$, the tensile stiffness of bolt $k_{f 1}=9 \times 10^{6} \mathrm{~N} / \mathrm{m}$, the stiffness of bolt when the bolt is loosened $k_{f 2}=0 \mathrm{~N} / \mathrm{m}$, the stiffness of the unloosened bolt $k_{f 3}=2 \times 10^{9} \mathrm{~N} / \mathrm{m}$, and the mass of the bearing support $m_{6}=1.1 \mathrm{~kg}$.

The spectrum cascade of the right journal (mass 5) and the right bearing support (mass 6) in the vertical direction ( $y$-direction) is as shown in Figure 10. When the eccentricity is $0.1 \leq e<0.22 \mathrm{~mm}$, since the support does not loosen, there is no fraction frequency in the vibration response of the journal and the right bearing support at this time. At the same time, it can be seen from Figure 10(b) that with the increase of the eccentricity $e$, the amplitude of the rotating frequency $f_{r}$ of the right bearing support is increased continuously. This is because the vertical displacement of the support at this time is much smaller than the looseness clearance. When the eccentricity is $0.22 \leq e \leq 0.43 \mathrm{~mm}$, a slight looseness has just occurred. In the spectrum cascade, a small fraction frequency appears, as shown in Figure 10. When the eccentricity $e>0.43 \mathrm{~mm}$, because the looseness of the support is obvious, there is an obvious $f_{r} / 2$ fraction frequency, and its amplitude is greater than the amplitude of the frequency $f_{r}$ (see Figure 10(b)).

The orbits and Poincaré maps of the right journal with different disc eccentricities under Working Condition 2 are shown in Figure 11. It can be seen that when the eccentricity $e$ is small ( $e=0.1 \mathrm{~mm})$, no looseness occurs, and the orbit of the right journal is an ellipse. The Poincaré maps show that the motion is period 1 . When the eccentricity $e=0.3 \mathrm{~mm}$, the orbit of the right journal presents an obvious "cylindrical," and the Poincaré maps show chaos. When the eccentricity $e=0.9 \mathrm{~mm}$, the "cylindrical" orbit of the right journal is more obvious, indicating that the increase of the eccentricity $e$ has aggravated the looseness.

The vibration waveforms of the right journal and the right bearing support in the vertical direction ( $y$-direction) with different eccentricities under Working Condition 2 are shown in Figures 12 and 13, respectively. It can be seen that, with the increase of the eccentricity $e$, the amplitude of the vibration waveforms of the journal and the support in the $y$ direction becomes larger, which also shows that the looseness becomes severe. 


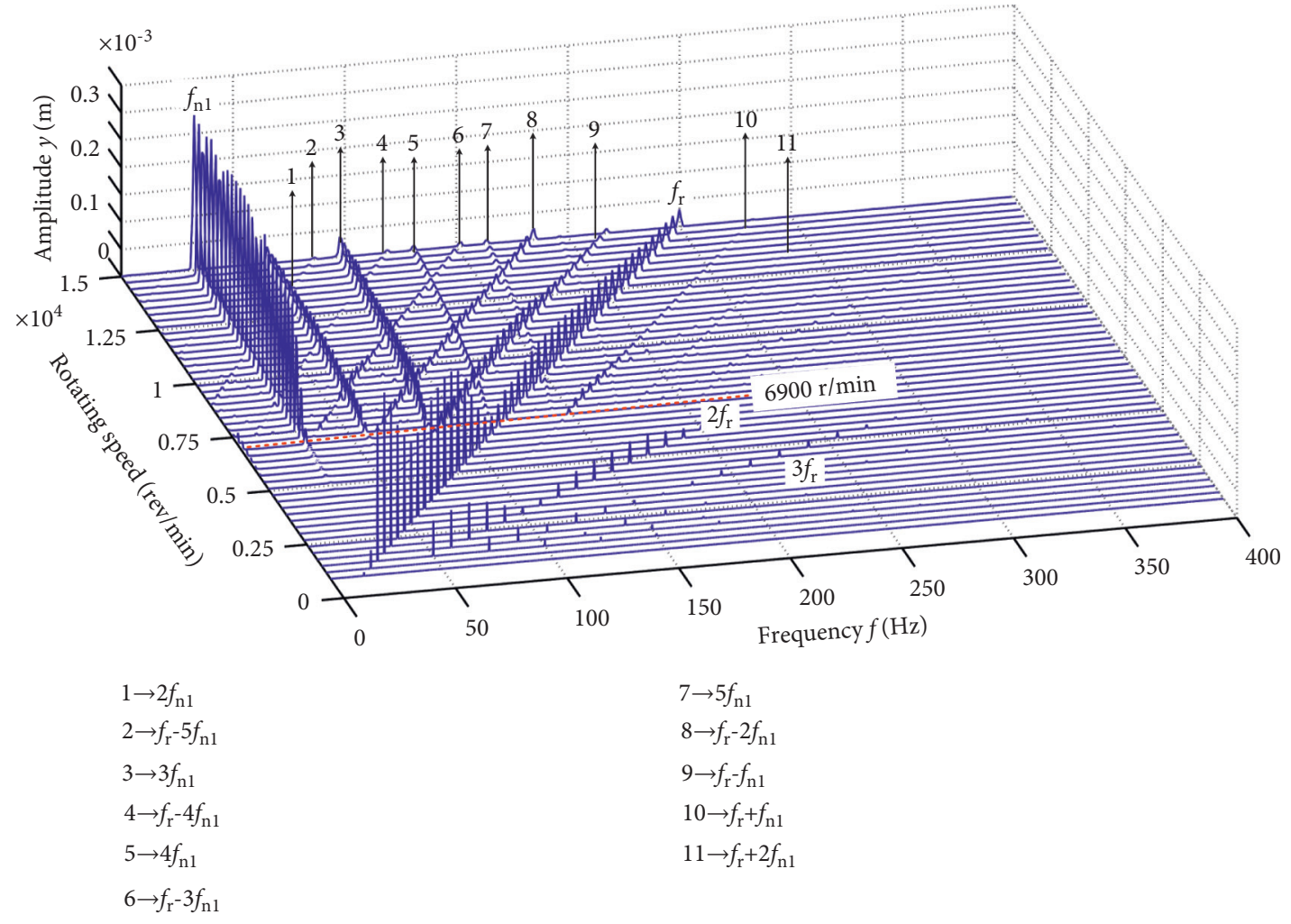

FIgURE 3: Spectrum cascade of the right journal.

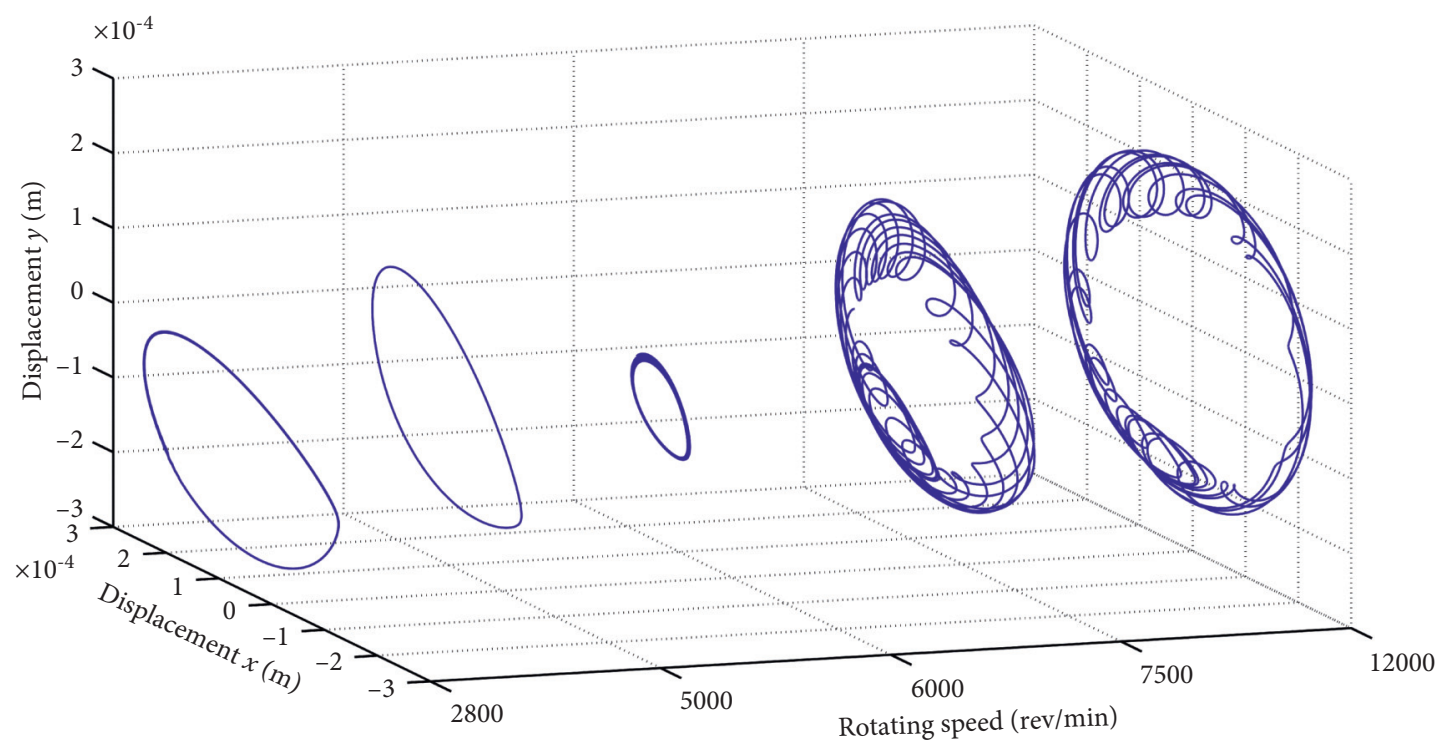

(a)

Figure 4: Continued. 


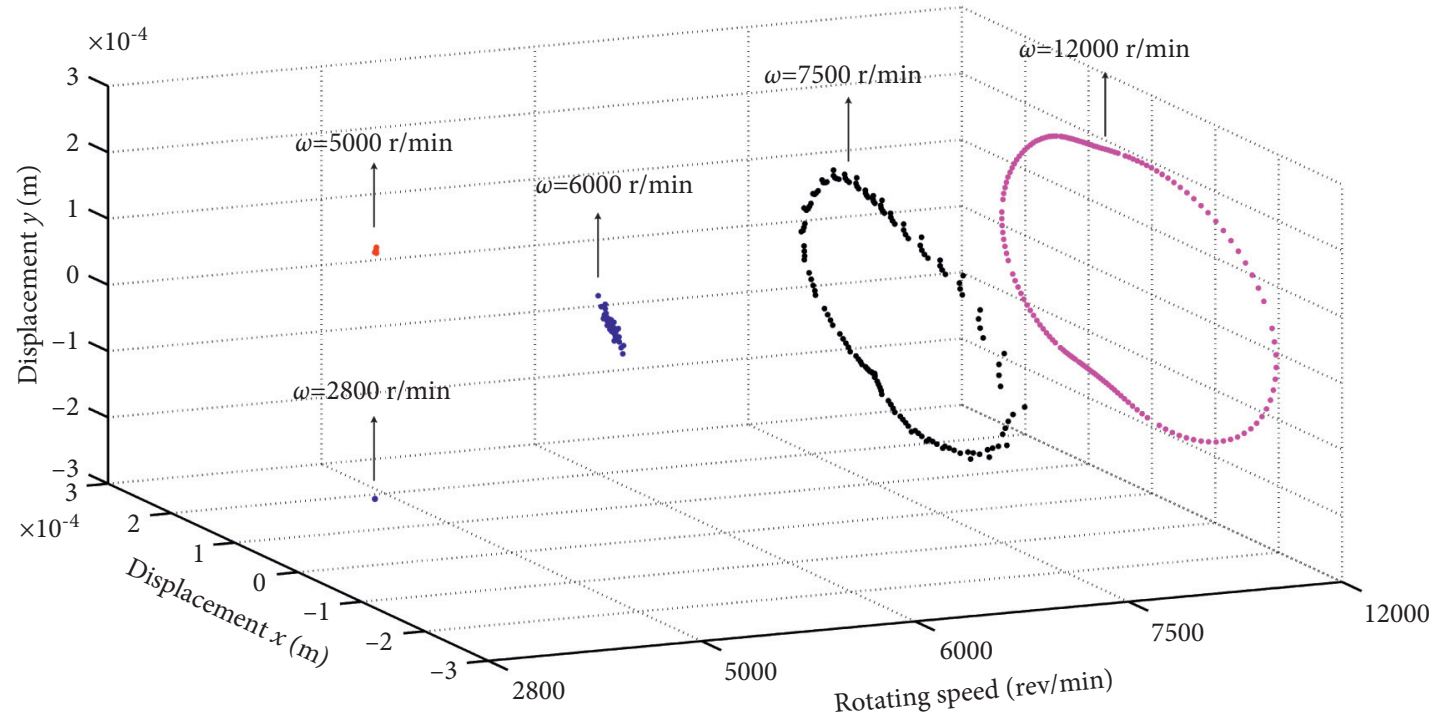

(b)

Figure 4: Rotor orbits and Poincaré maps of the right journal. (a) Rotor orbits. (b) Poincaré maps.

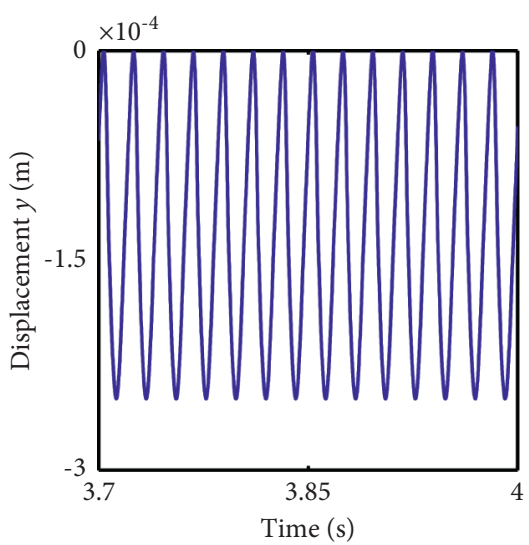

(a)

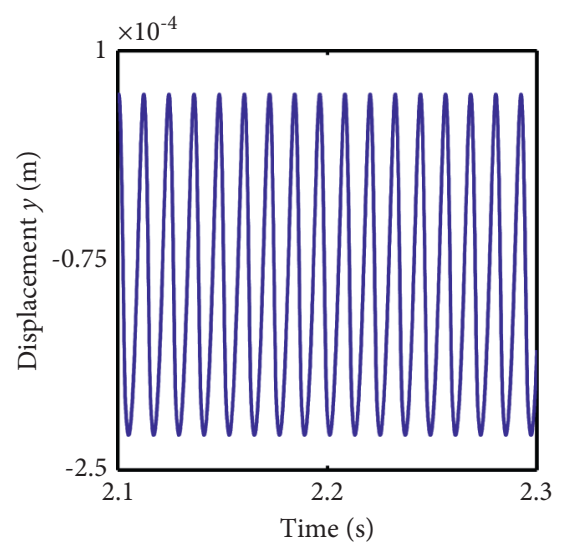

(b)

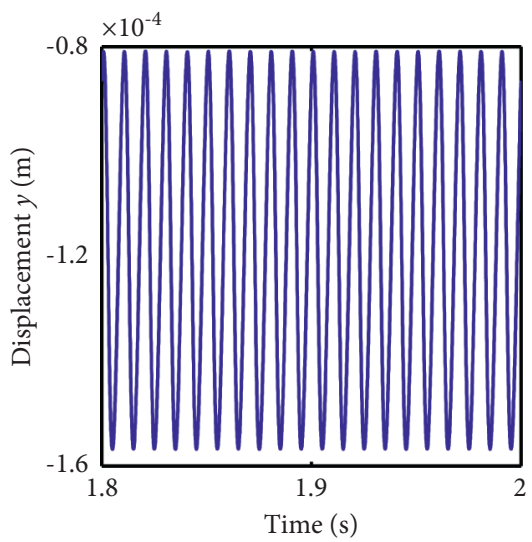

(c)

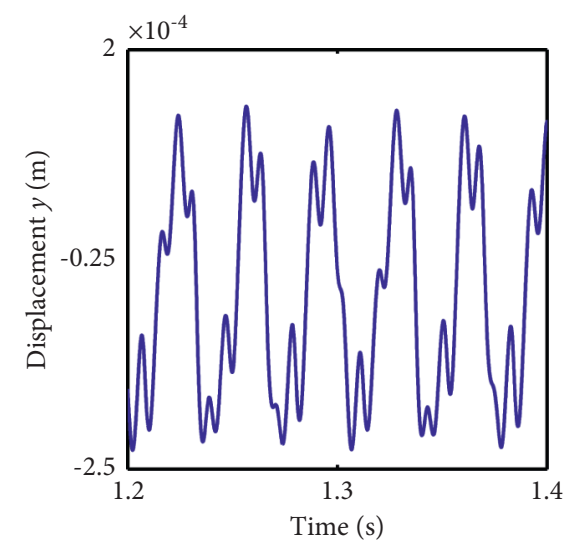

(d)

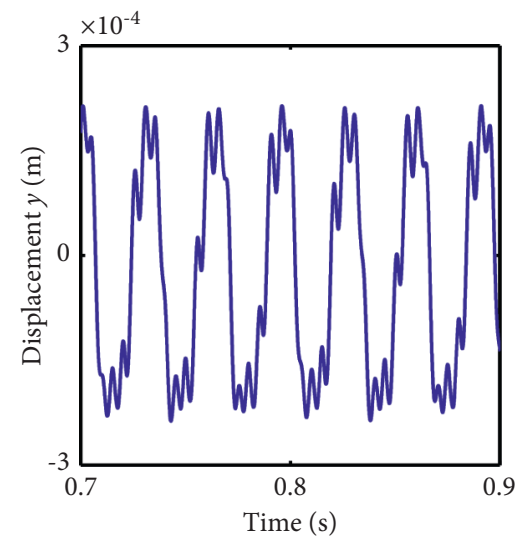

(e)

FIGURE 5: Vibration waveforms of the right journal. (a) $\omega=2800 \mathrm{r} / \mathrm{min}$, (b) $\omega=5000 \mathrm{r} / \mathrm{min}$, (c) $\omega=6000 \mathrm{r} / \mathrm{min},(\mathrm{d}) \omega=7500 \mathrm{r} / \mathrm{min}$, and (e) $\omega=12000 \mathrm{r} / \mathrm{min}$. 


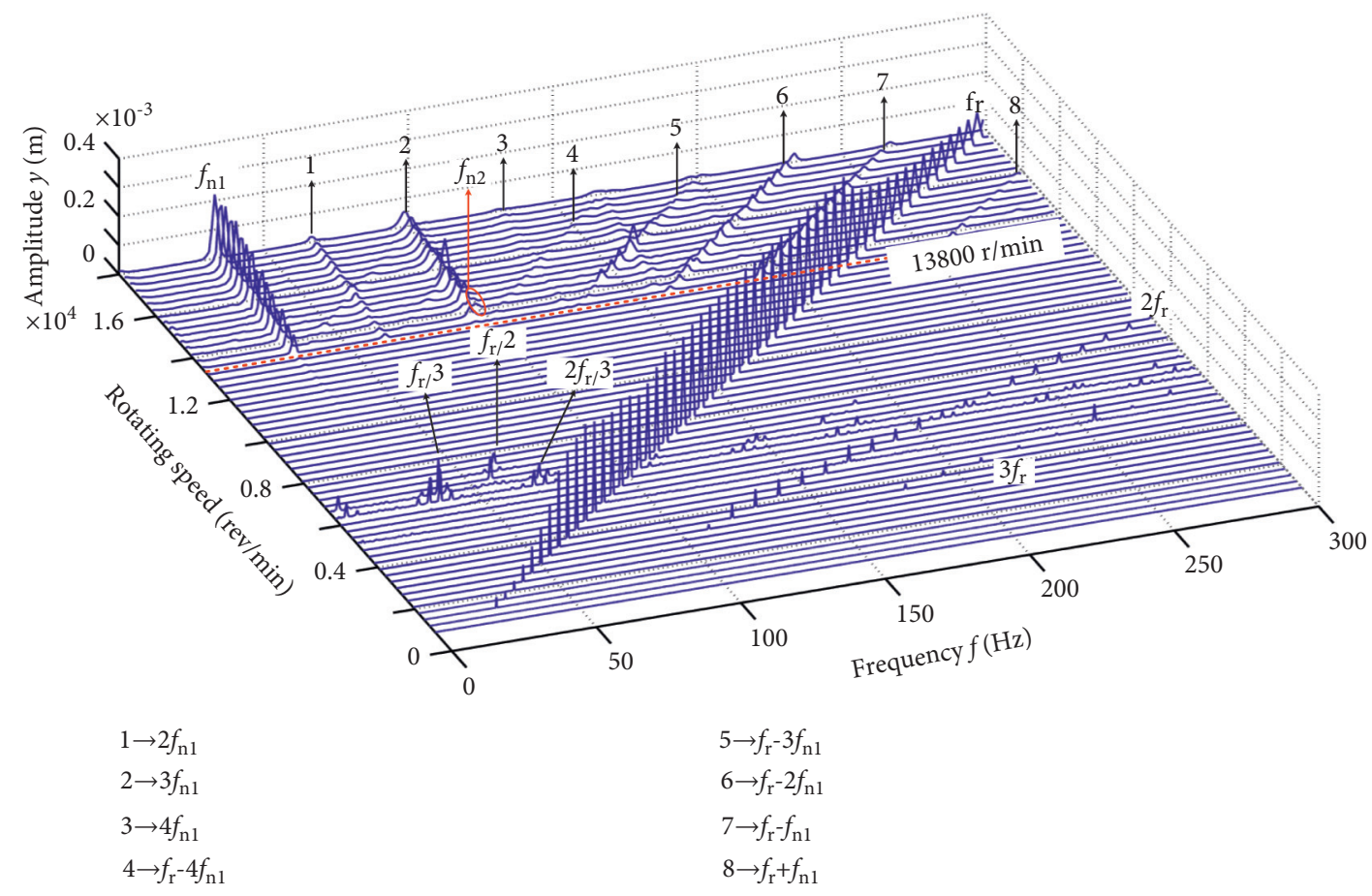

(a)

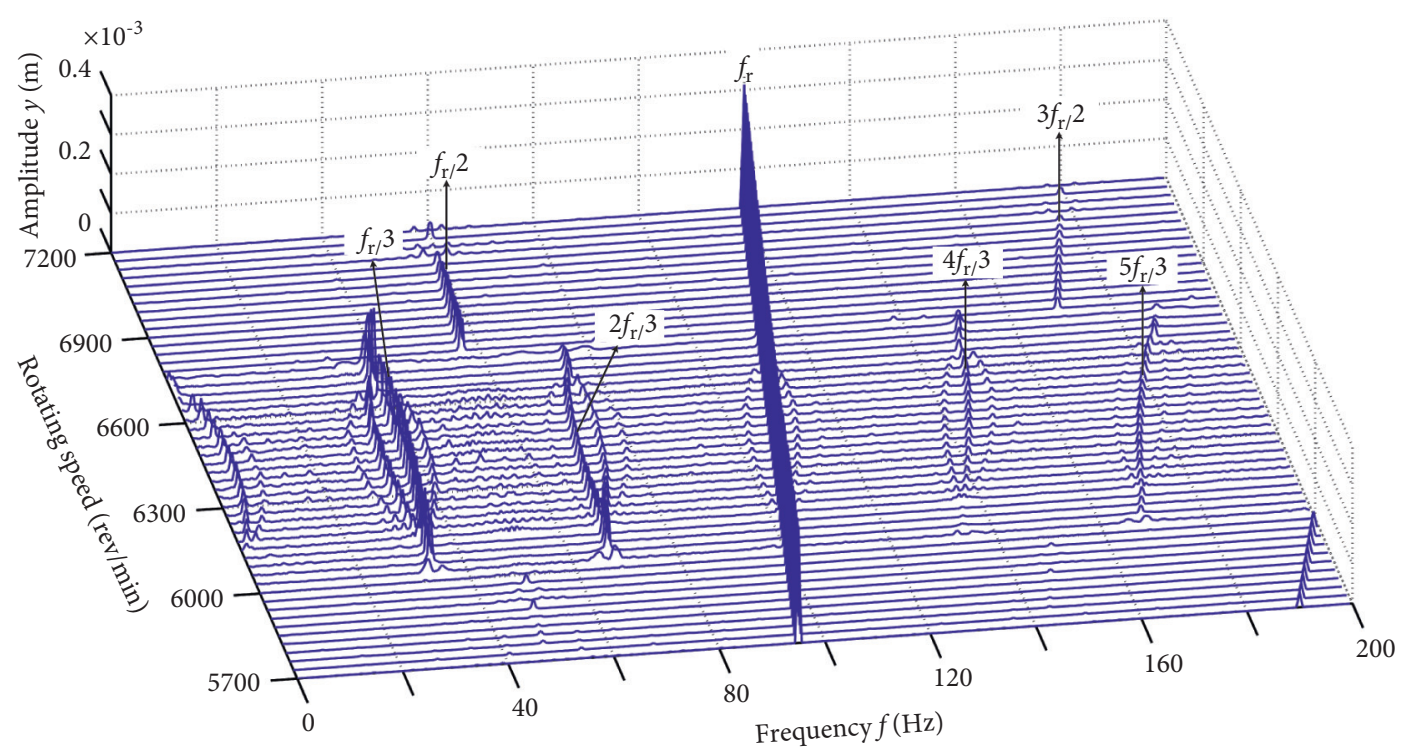

(b)

Figure 6: Spectrum cascade of the right journal. (a) $\omega \in[600,18000] \mathrm{r} / \mathrm{min}$ and (b) $\omega \in[5700,7200] \mathrm{r} / \mathrm{min}$.

4.2. Influence of Loose Clearance. Taking the looseness clearance as the control parameter, other parameters of the system are as follows: the rotating speed $\omega=6900 \mathrm{r} / \mathrm{min}$, the unbalance $m_{3} e_{1}=m_{4} e_{2}=1.1838 \times 10^{-4} \mathrm{~kg} \cdot \mathrm{m}$, the tensile stiffness of bolt $k_{f 1}=9 \times 10^{7} \mathrm{~N} / \mathrm{m}$, the stiffness of bolt when the bolt is loosened $k_{f 2}=2 \times 10^{3} \mathrm{~N} / \mathrm{m}$, the stiffness of unloosened bolt $k_{f 3}=2 \times 10^{10} \mathrm{~N} / \mathrm{m}$, and the mass of the bearing support $m_{6}=1.1 \mathrm{~kg}$.

The spectrum cascade of the right journal (mass 5) and the right bearing support (mass 6) in the vertical direction ( $y$-direction) is shown in Figure 14. When the looseness clearance is $1 \times 10^{-6} \leq \delta<0.2674 \times 10^{-3} \mathrm{~m}$, because the looseness clearance in this section is small, it is easy to cause the bearing support to contact the top of the bolt, and the displacement of bearing support will be limited by the bolt. Therefore, in this looseness clearance interval, the stiffness value $k_{f}$ will change three times, including the loose stiffness $k_{f 2}$ of the bolt, the stiffness $k_{f 3}$ when the bearing support is pressed against the foundation, and the tensile stiffness $k_{f 1}$ of the bolt. As shown in Figures 14(a) and 14(b), there is no fraction frequency, but multiple frequency is the main component. Because the looseness clearance is small at this 


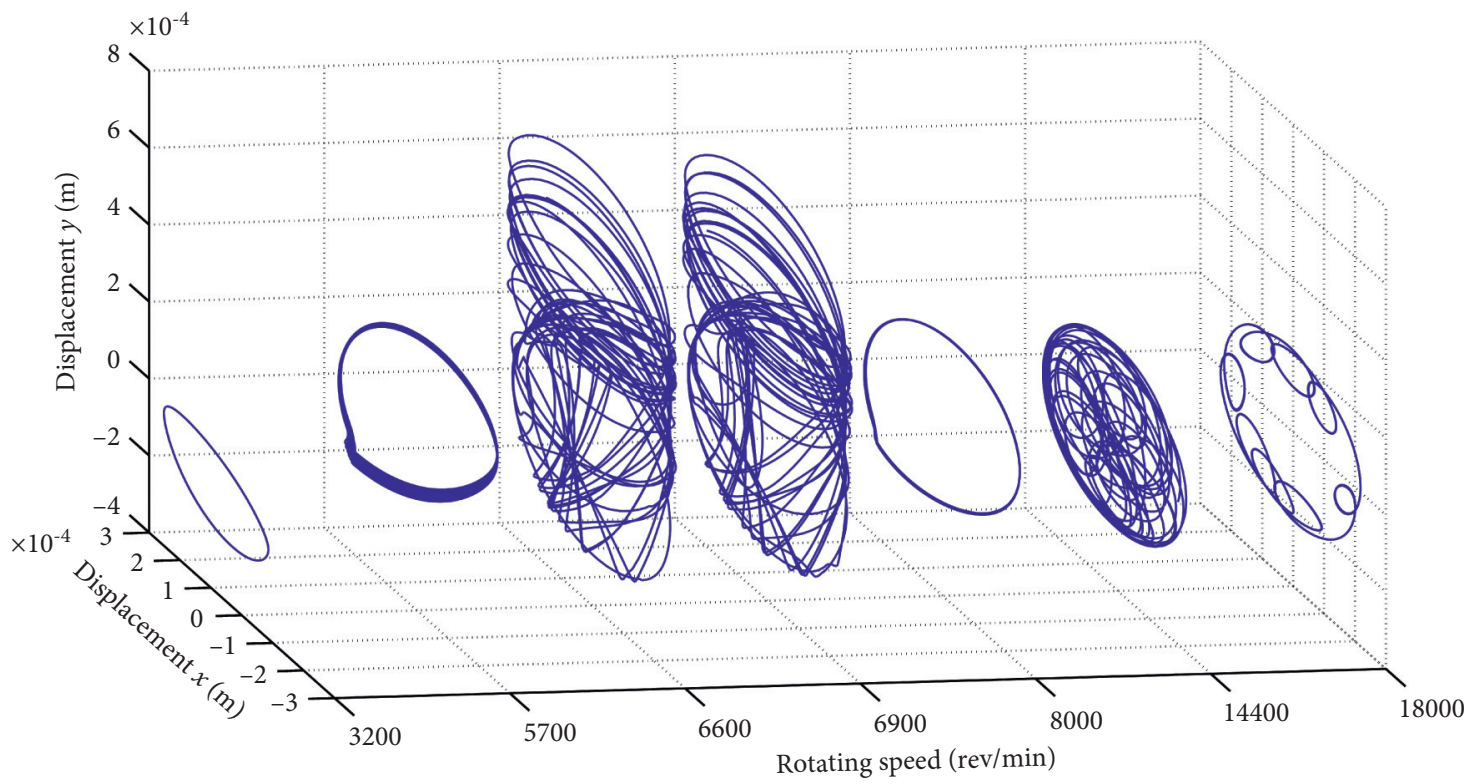

(a)

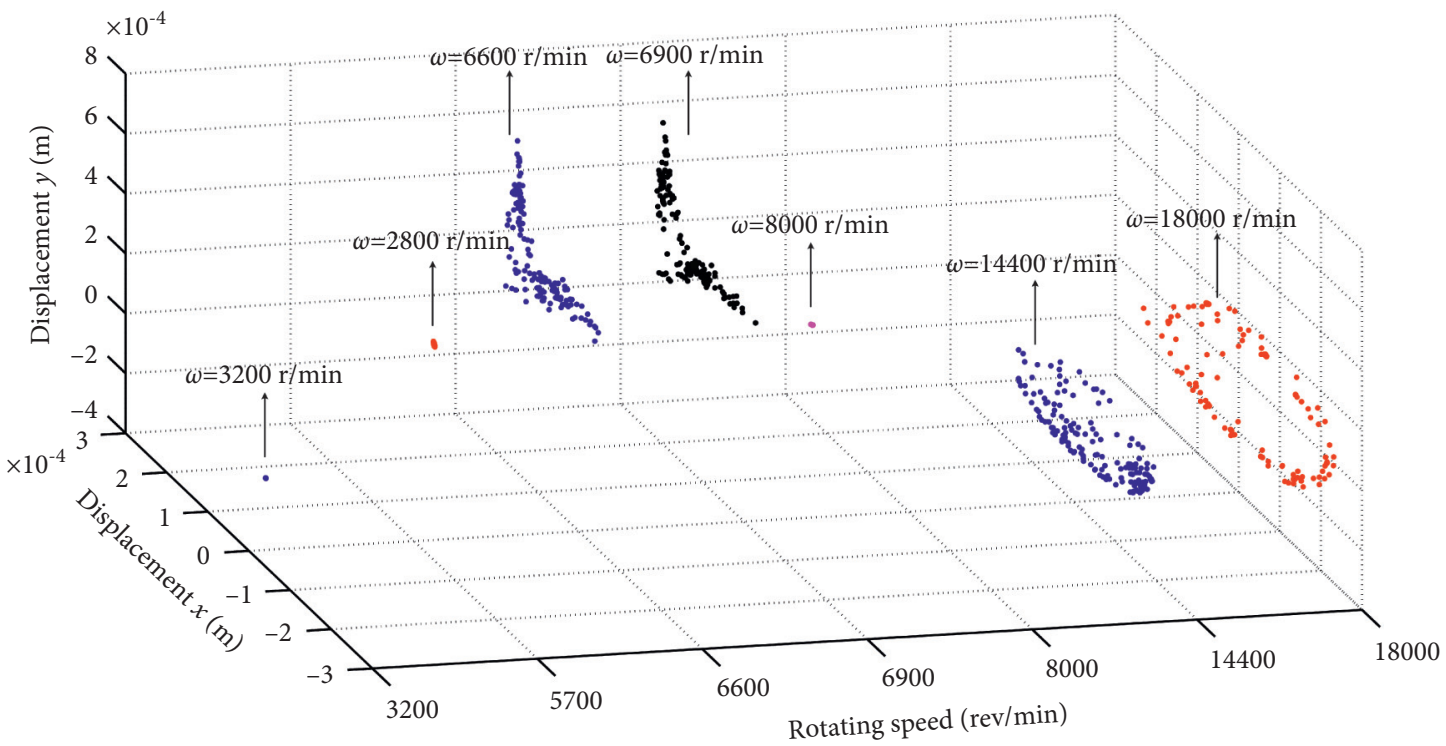

(b)

Figure 7: Rotor orbits and Poincaré maps of the right journal. (a) Rotor orbits. (b) Poincaré maps.

time, the upward movement of the support will be restricted by the bolt, so the amplitude of the support response will improve as the looseness clearance increases, as shown in Figure 14(b).

With the increase of the looseness clearance, when $\delta=0.2674 \times 10^{-3} \mathrm{~m}$, the upward movement of the support sometimes exceeds the loosening clearance and is restricted by the bolt and sometimes does not exceed the looseness clearance. At this time, the number of changes in the stiffness value $k_{f}$ converts from three to two, so in the three-dimensional spectrum, it is continuous, as shown in Figure 14.

When the looseness clearance is $0.3007 \times 10^{-3} \leq \delta \leq 1 \times 10^{-3} \mathrm{~m}$, the looseness clearance is large at this time, so the bearing support will not contact the top of the bolt. Therefore, the stiffness value $k_{f}$ only changes twice, namely the bolt looseness stiffness $k_{f 2}$ and the stiffness $k_{f 3}$ when the bearing support is compressed with the foundation. It can be seen from Figure 14 that the fraction frequency such as $f_{r} / 2,3 f_{r} / 2$, and $5 f_{r} / 2$ appear, and the spectrum of the bearing support shows that the amplitude of the fraction frequency $f_{r} / 2$ is very large, almost equivalent to the amplitude of the rotating frequency $f_{r}$. Because the motion of the support will not be restricted by the bolt at this time, so the vibration amplitude of the bearing support will not improve when the looseness clearance increases, as shown in Figure 14(b).

The rotor orbits and Poincaré maps of the right journal under different looseness clearance in Working Condition 2 


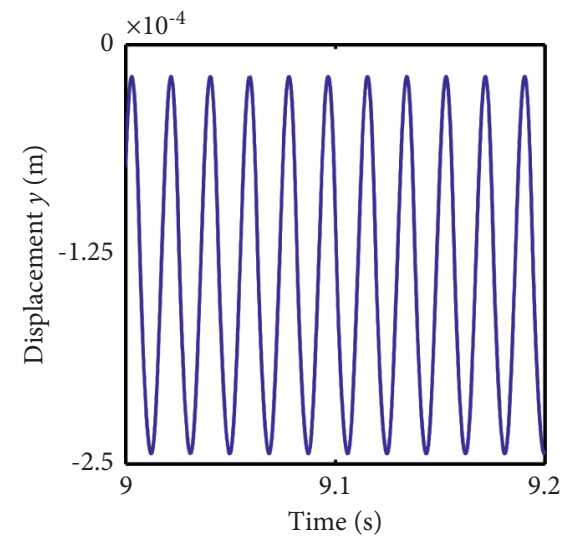

(a)

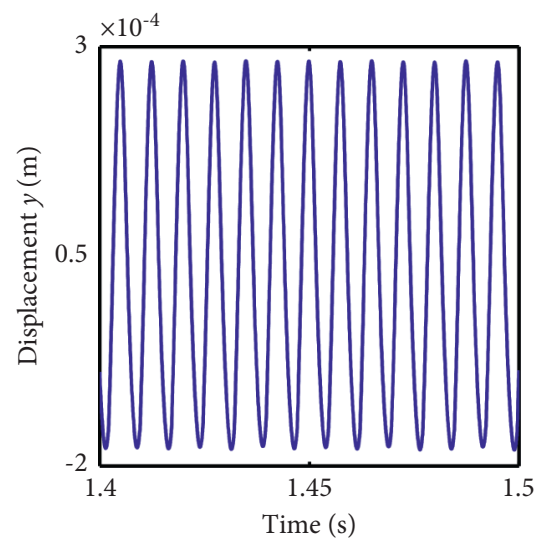

(d)

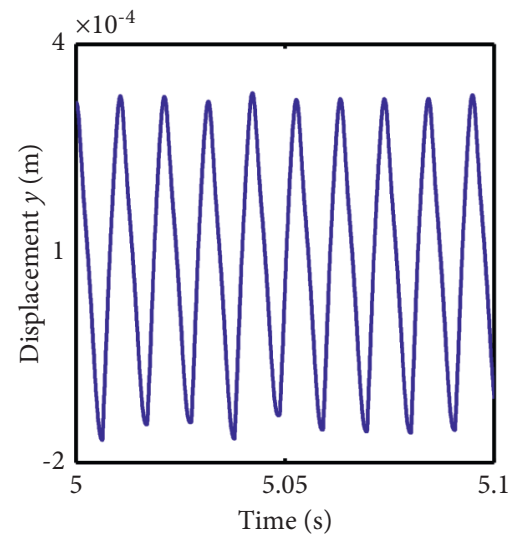

(b)

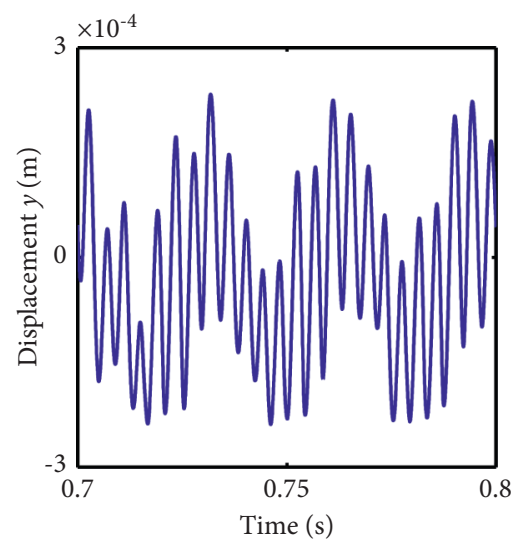

(e)

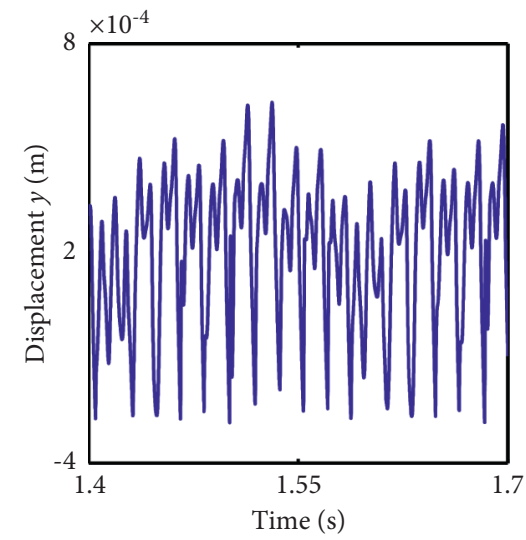

(c)

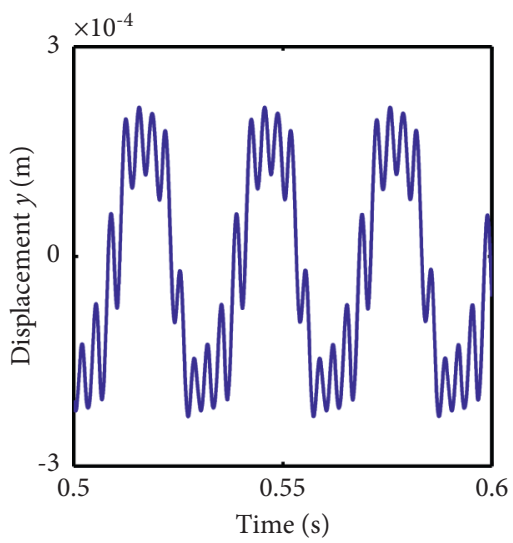

(f)

Figure 8: Vibration waveforms of the right journal. (a) $\omega=3200 \mathrm{r} / \mathrm{min}$, (b) $\omega=5700 \mathrm{r} / \mathrm{min}$, (c) $\omega=6900 \mathrm{r} / \mathrm{min},(\mathrm{d}) \omega=8000 \mathrm{r} / \mathrm{min}$, (e) $\omega=14400 \mathrm{r} / \mathrm{min}$, and (f) $\omega=18000 \mathrm{r} / \mathrm{min}$.

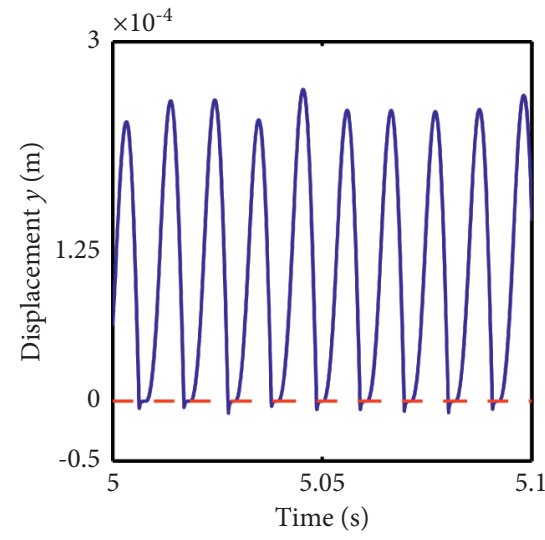

(a)

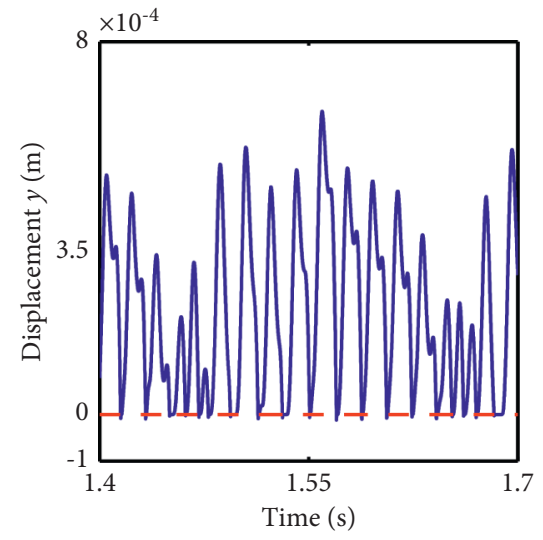

(b)

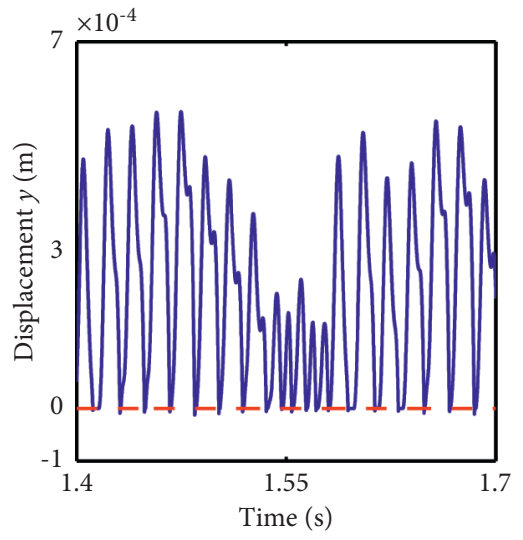

(c)

Figure 9: Vibration waveforms of the right bearing support. (a) $\omega=5700 \mathrm{r} / \mathrm{min}$, (b) $\omega=6600 \mathrm{r} / \mathrm{min}$, and (c) $\omega=6900 \mathrm{r} / \mathrm{min}$.

are shown in Figure 15. It can be seen that with the increase of the looseness clearance, the orbit changes from the insignificant "cylindrical" when $\delta=0.1 \times 10^{-3} \mathrm{~m}$ to the obvious "cylindrical" when $\delta=1 \times 10^{-3} \mathrm{~m}$. The Poincaré maps also show that the motion state of the system gradually changes from quasiperiodic to chaotic, as the looseness clearance increases.

The vibration waveforms of the right journal and the right bearing support in the vertical direction ( $y$-direction) with different looseness clearance under Working Condition 


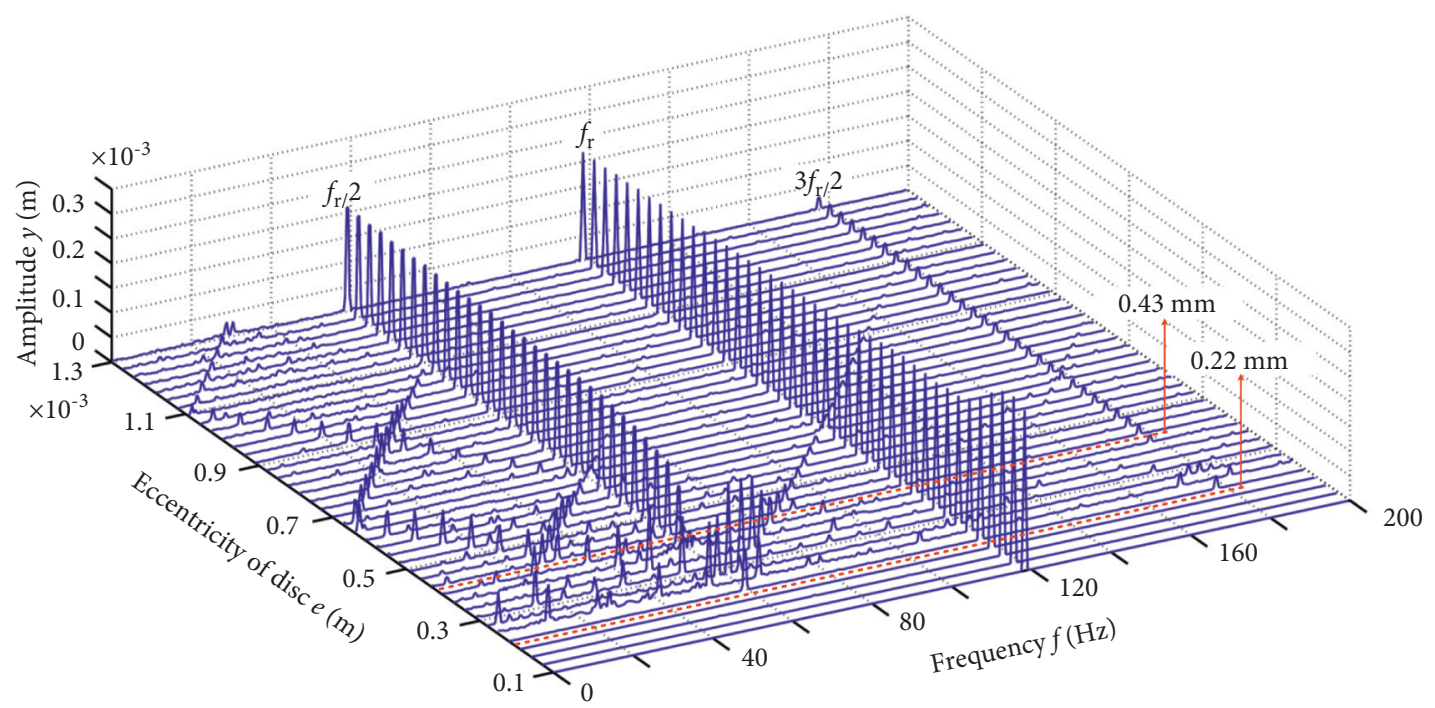

(a)

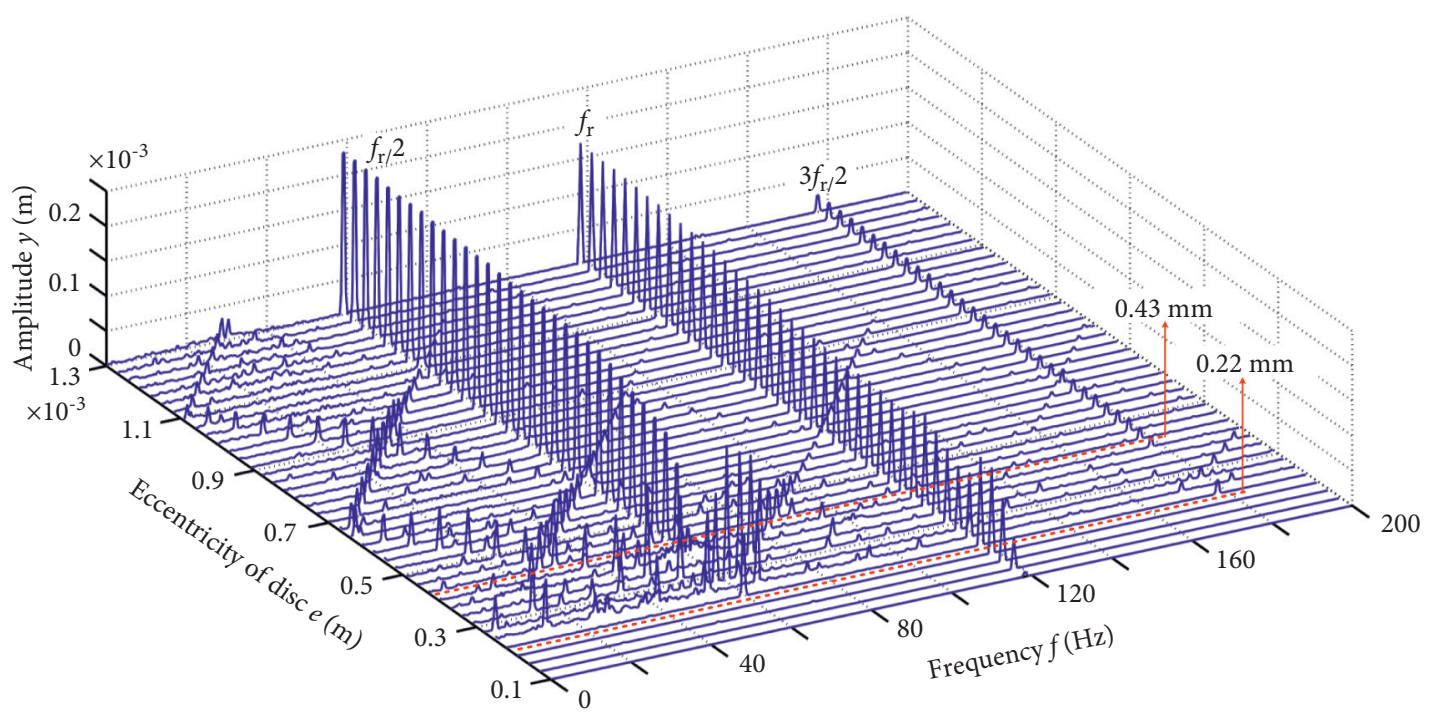

(b)

FIgURE 10: Spectrum cascades of the system with the change of the unbalance of two discs. (a) Spectrum cascade of right journal. (b) Spectrum cascade of right bearing support.

2 are shown in Figures 16 and 17. It can be seen from Figure 17(a) that when the looseness clearance $\delta=0.1 \times 10^{-3} \mathrm{~m}$, the movement of the support can be restricted by both the foundation and the bolt. Therefore, the upper and lower parts of the vibration waveforms of the support have clipping. But the results are obviously different. The clipping of the upper part is sharper, while the clipping of the lower part is flat. This is because the loose bearing cap moves upward, and the time of exceeding the looseness is much shorter than the time of contact with the foundation.

It can be seen from Figure 17(b) that when the looseness clearance $\delta=0.27 \times 10^{-3} \mathrm{~m}$, the upward movement of the support sometimes exceeds the looseness clearance and is restricted by the bolt but sometimes does not exceed the looseness clearance. The number of changes in the stiffness $k_{f}$ is between two and three, so the upper part of the vibration waveforms of the support is not always clipping. It can be seen from Figure 17(c) that when the looseness clearance $\delta=1 \times 10^{-3} \mathrm{~m}$, due to the large looseness clearance, the displacement of the support will not exceed the looseness clearance and will not be restricted by the tensile force of the bolt, so the vibration waveforms occur clipping only once and only in the lower part.

4.3. Influence of the Mass of the Right Bearing Support. Taking the bearing support $m_{6}$ as the control parameter, other parameters of the system are as follows: the rotating speed $\omega=6900 \mathrm{r} / \mathrm{min}$, the unbalance $m_{3} e_{1}=\mathrm{m}_{4} e_{2}=$ $1.1838 \times 10^{-4} \mathrm{~kg} \cdot \mathrm{m}$, the looseness clearance $\delta=1 \mathrm{~mm}$, the tensile stiffness of bolt $k_{f 1}=9 \times 10^{7} \mathrm{~N} / \mathrm{m}$, the stiffness of bolt when the bolt is loosened $k_{f 2}=2 \times 10^{3} \mathrm{~N} / \mathrm{m}$, and the unloosened bolt stiffness $k_{f 3}=2 \times 10^{10} \mathrm{~N} / \mathrm{m}$. 


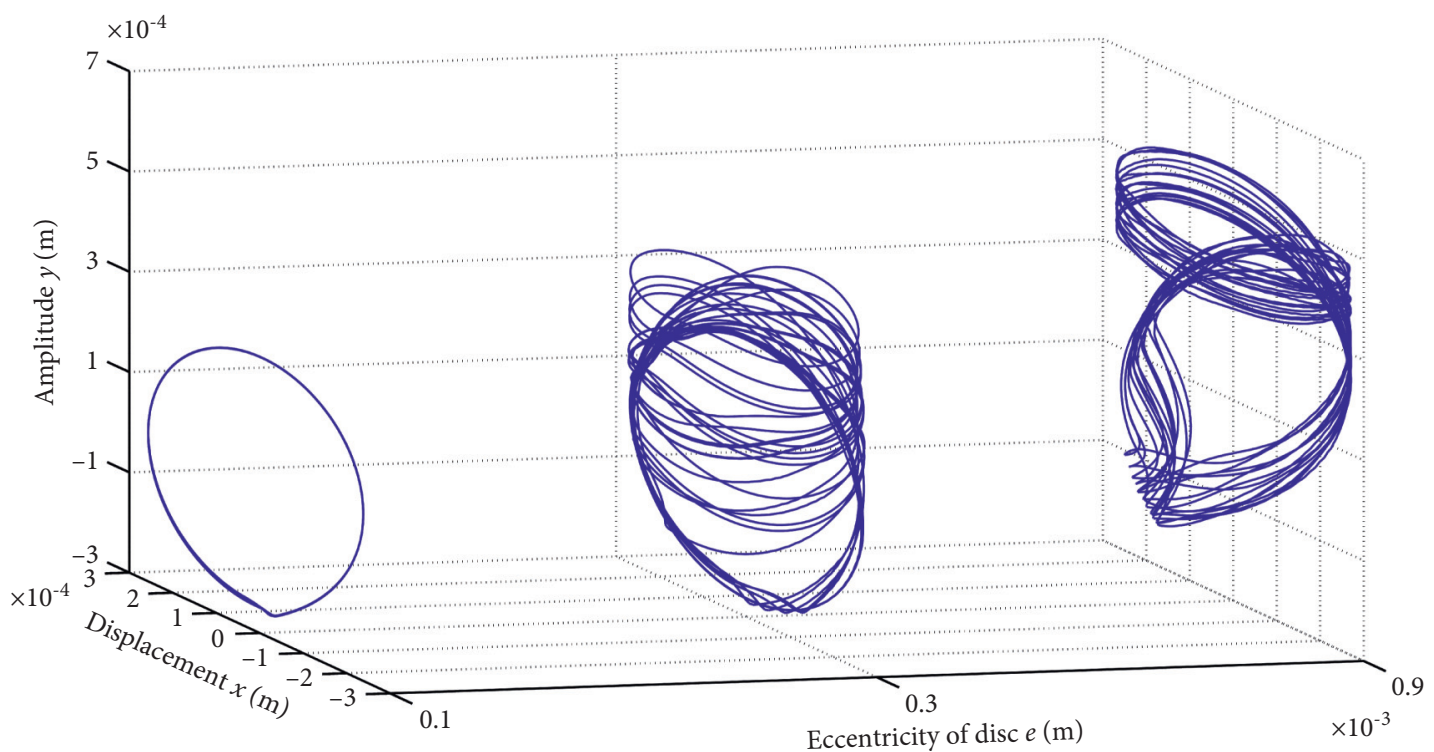

(a)

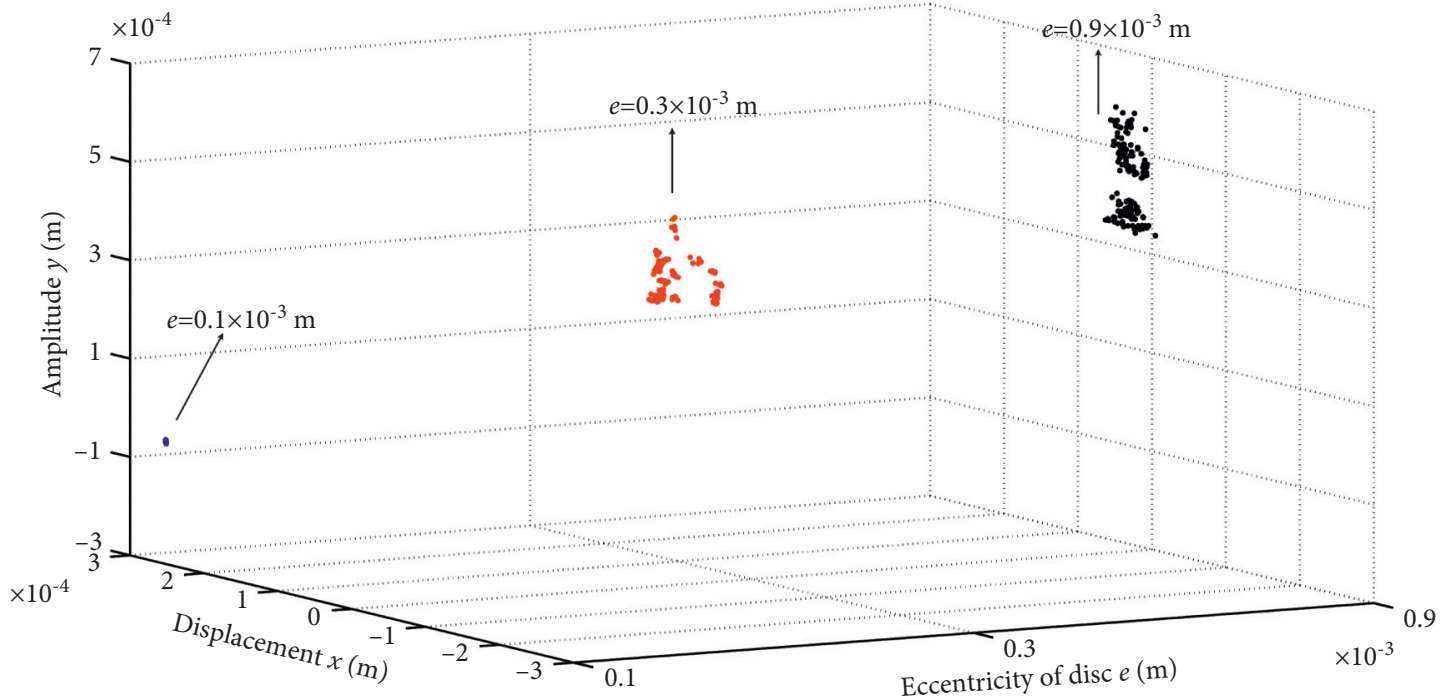

(b)

Figure 11: Rotor orbits and Poincaré maps of the right journal with the change of the unbalance of two discs. (a) Rotor orbits. (b) Poincaré maps.

The spectrum cascade of the right journal (mass 5) and the right bearing support (mass 6) in the vertical direction ( $y$-direction) is shown in Figure 18. When the mass of the bearing support is $0.5 \leq m_{6}<0.6 \mathrm{~kg}$, the looseness is more severe due to the small mass of the support, and a large number of continuous spectra appear in the spectrum. As can be seen from Figure 18(b), the amplitude of rotating frequency $f_{r}$ is the largest, which also shows that the looseness is obvious. When the bearing support mass $m_{6}=0.6 \mathrm{~kg}$, the amplitude of the fraction frequency $f_{r} / 2$ is the largest. With the increase of the support mass, the amplitude of $f_{r} / 2$ gradually decreases. After $m_{6} \geq 1.25 \mathrm{~kg}, f_{r} / 2,3 f_{r} / 2$, and $5 f_{r} / 2$ components disappeared. This also shows that the larger bearing pedestal mass can restrain the occurrence of looseness.
The orbits and Poincaré maps of the right journal with different right bearing support mass $\mathrm{m} 6$ under Working Condition 2 are shown in Figure 19. It can be seen that when the bearing mass $m_{6}$ is small $\left(m_{6}=0.55,1 \mathrm{~kg}\right)$, the "cylindrical" orbits of the right journal are very obvious, and the Poincare maps show that the system is chaotic. With the increase of the support mass $m_{6}\left(m_{6}=1.5 \mathrm{~kg}\right)$, the "cylindrical" orbits of the right journal gradually change from obvious to inconspicuous. When $m_{6}=2 \mathrm{~kg}$, the orbits are no longer "cylindrical," and the Poincaré maps show that the system motion is almost in period 1 .

The vibration waveforms of the right journal and bearing support in the vertical direction ( $y$-direction) with different right bearing support mass $m_{6}$ under Working Condition 2 are shown in Figures 20 and 21, respectively. It can be seen 


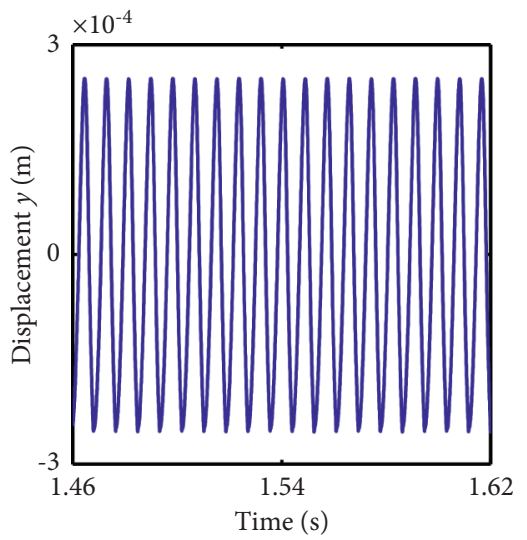

(a)

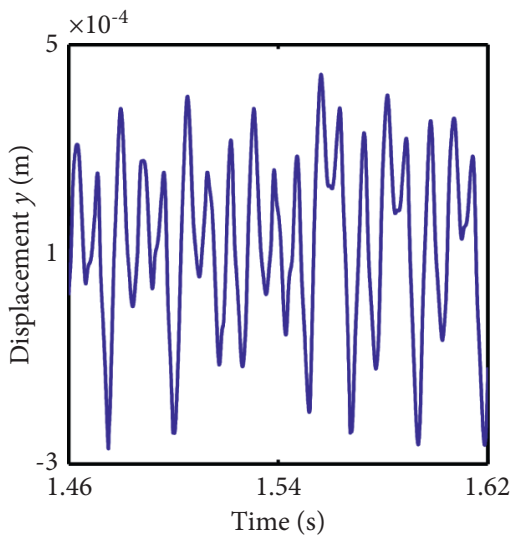

(b)

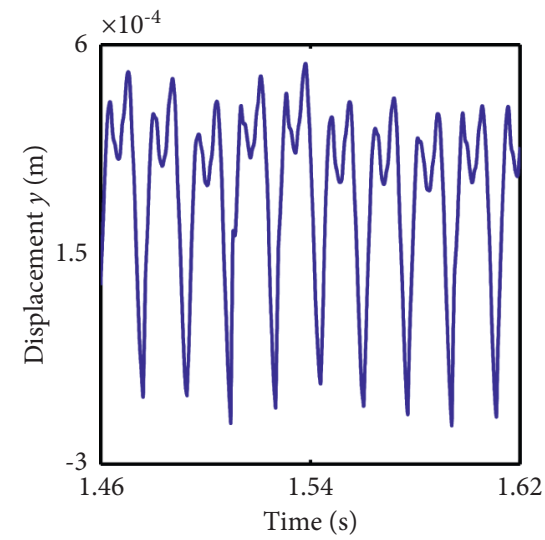

(c)

FIGURE 12: Vibration waveforms of the right journal with the change of the unbalance of two discs. (a) $e=0.1 \times 10^{-3} \mathrm{~m},(\mathrm{~b}) e=0.3 \times 10^{-3} \mathrm{~m}$, and (c) $e=0.9 \times 10^{-3} \mathrm{~m}$.

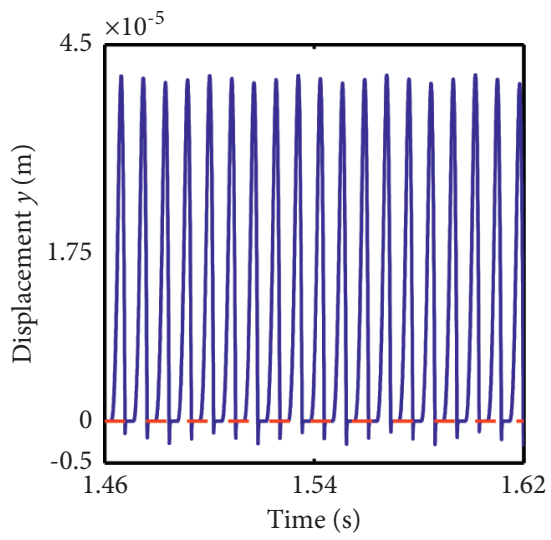

(a)

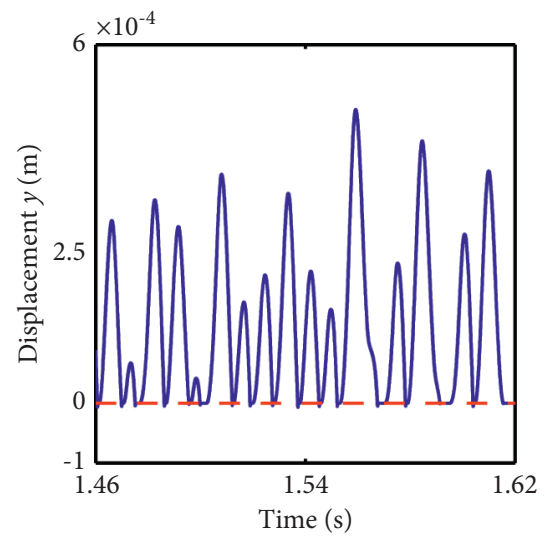

(b)

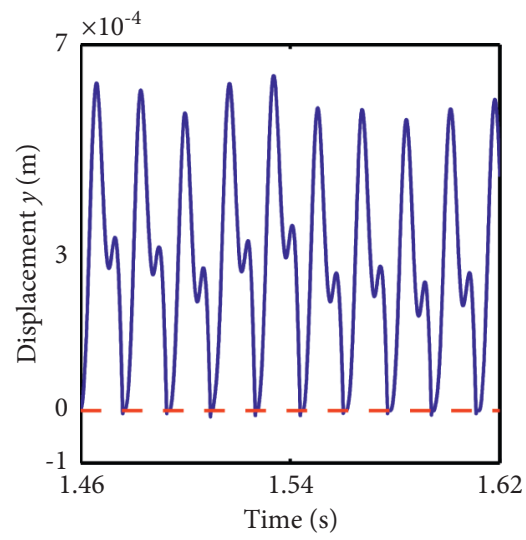

(c)

FIGURE 13: Vibration waveforms of the right bearing support with the change of the unbalance of two discs. (a) $e=0.1 \times 10^{-3} \mathrm{~m}$, (b) $e=0.3 \times 10^{-3} \mathrm{~m}$, and (c) $e=0.9 \times 10^{-3} \mathrm{~m}$.

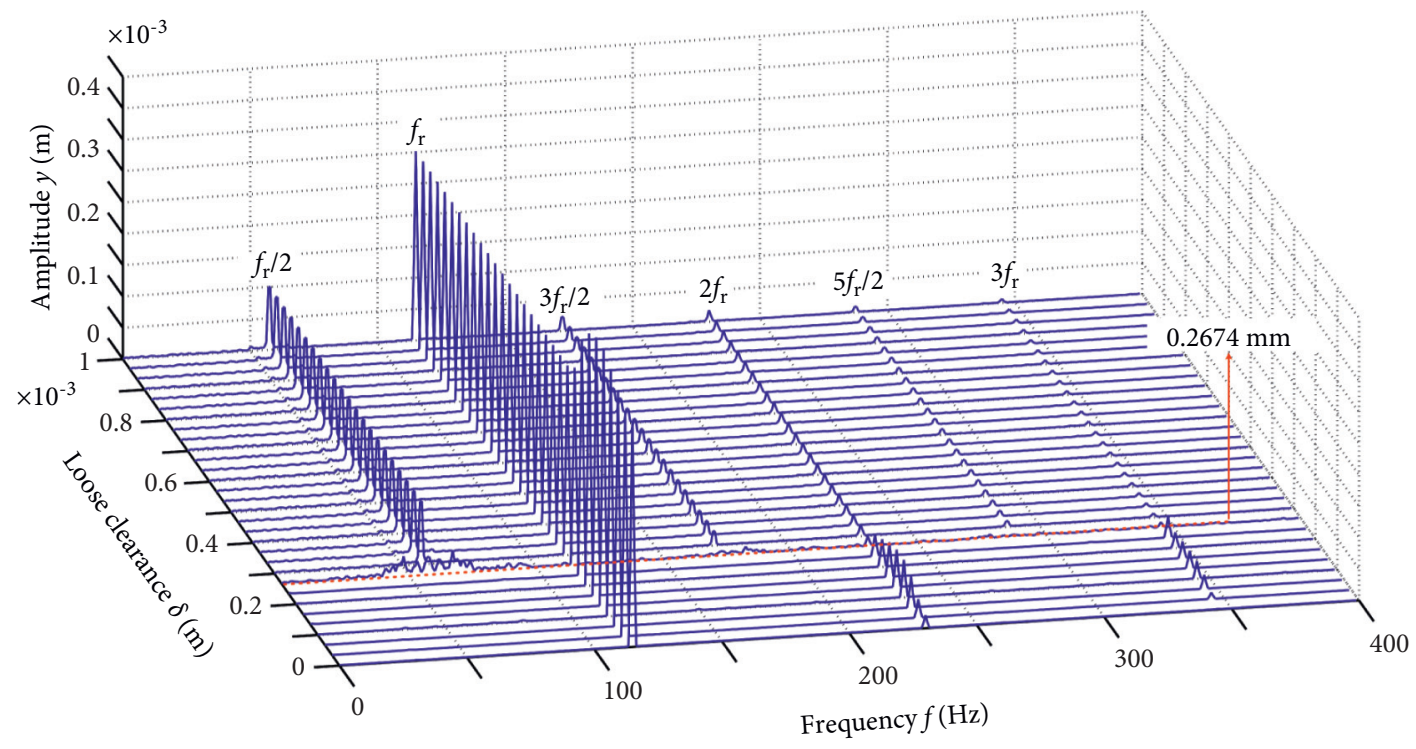

(a)

Figure 14: Continued. 


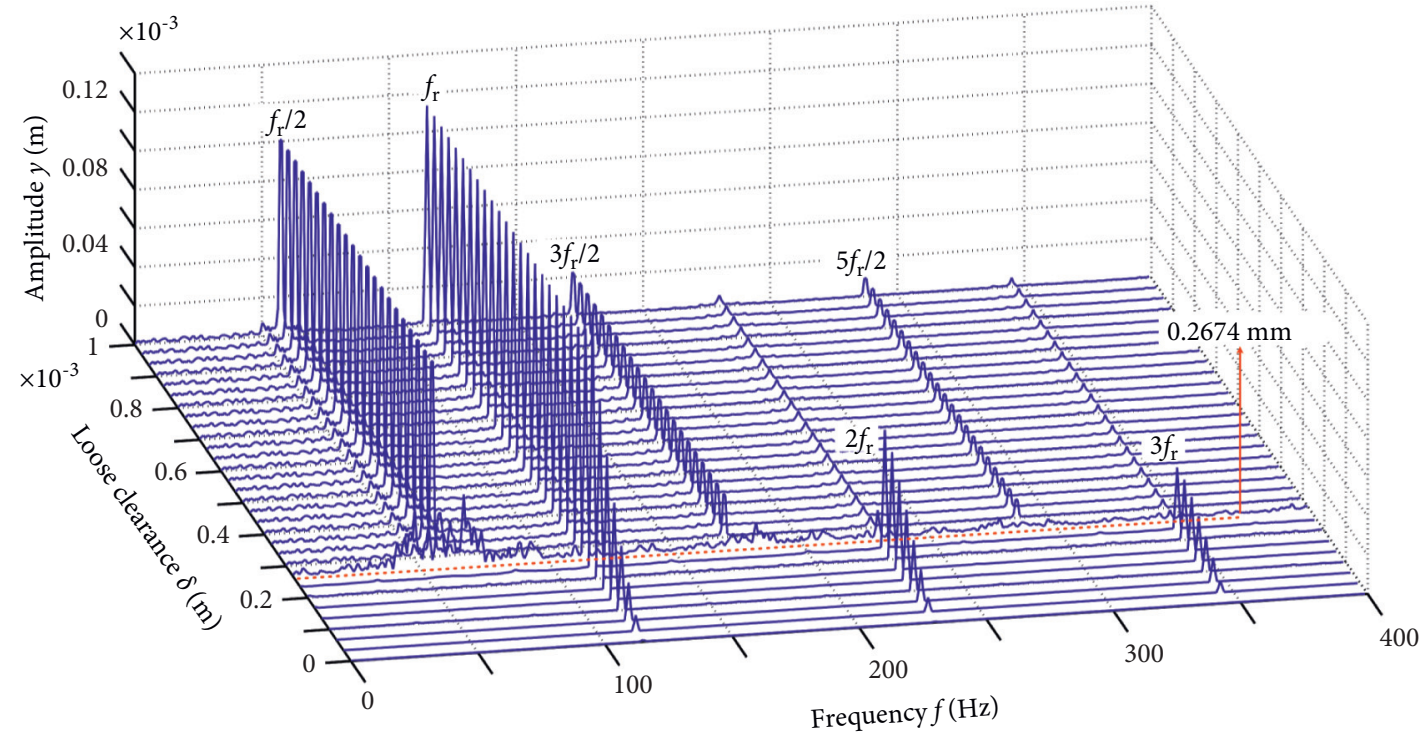

(b)

FIgURE 14: Spectrum cascades of the system with the change of the loose clearance. (a) Spectrum cascade of right journal. (b) Spectrum cascade of right bearing support.

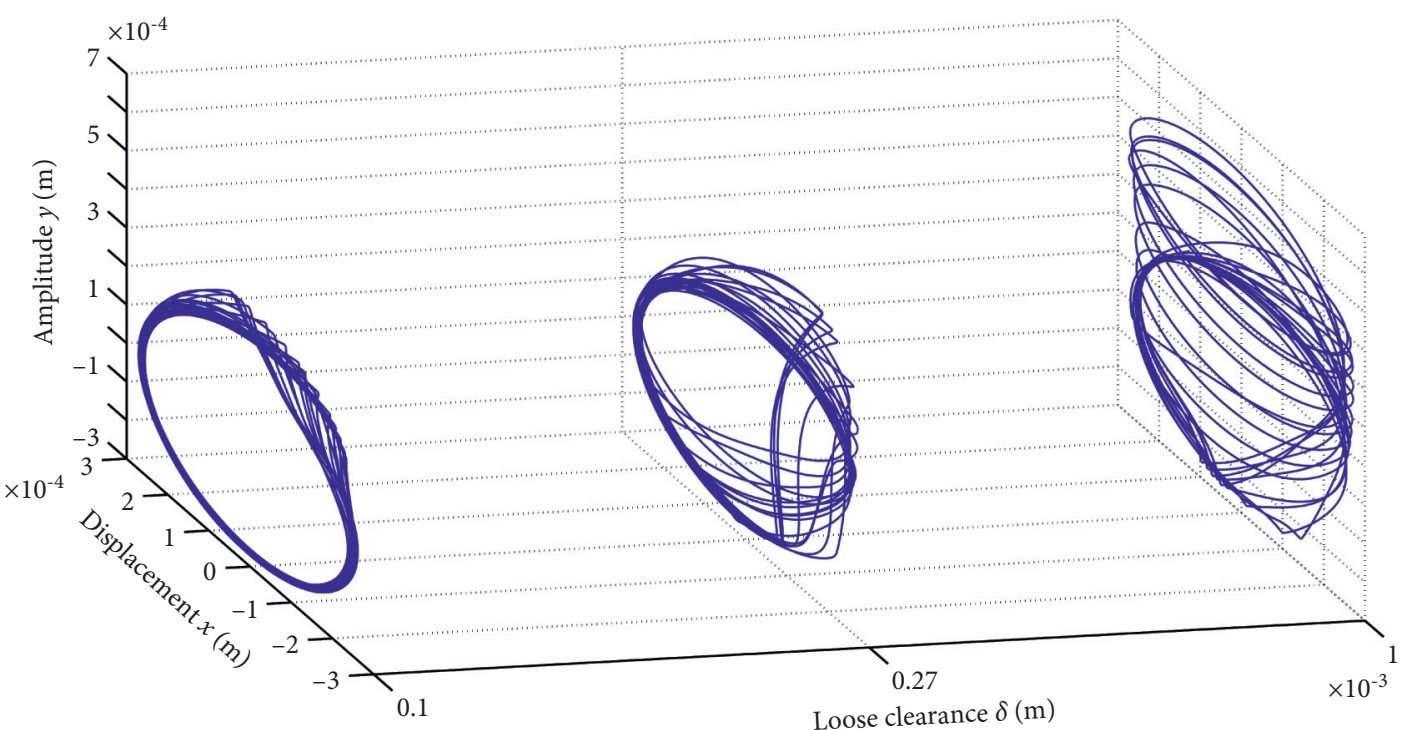

(a)

FIgURE 15: Continued. 


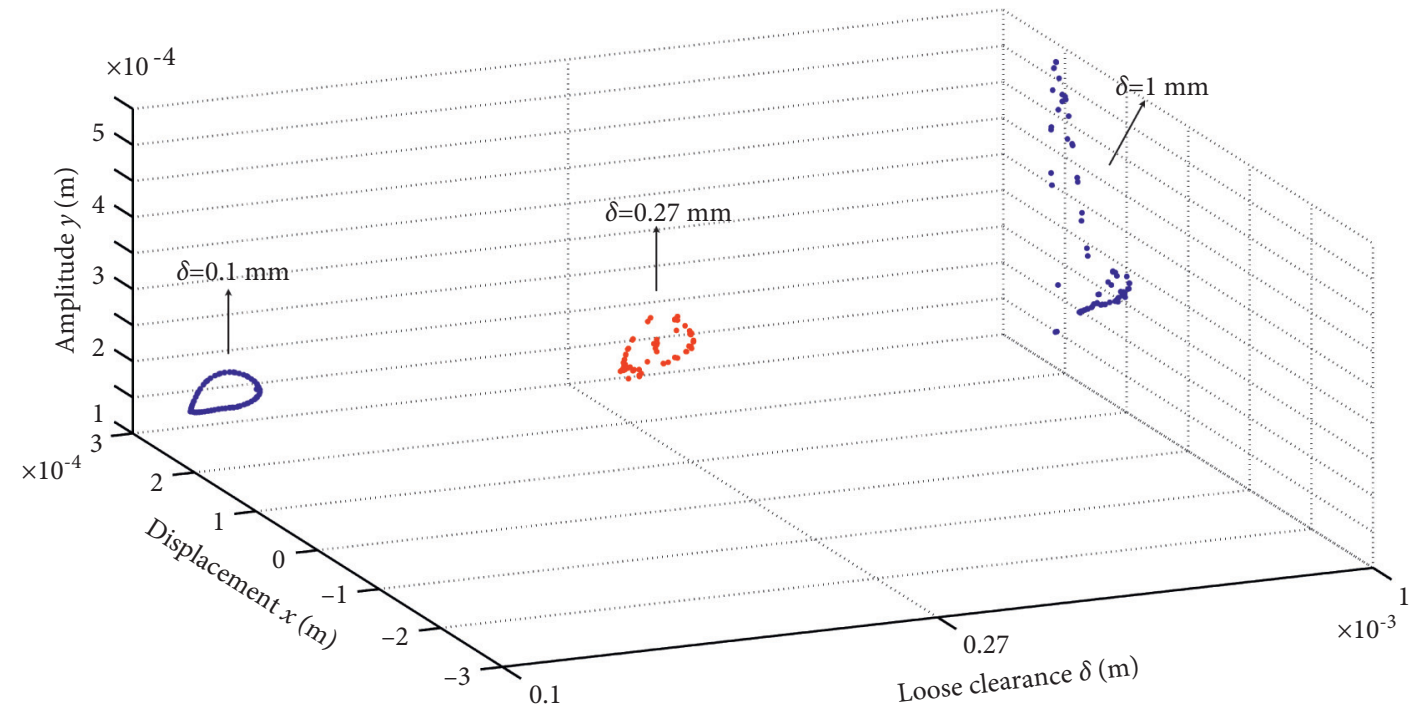

(b)

Figure 15: Rotor orbits and Poincaré maps of the right journal with the change of the loose clearance. (a) Rotor orbits. (b) Poincaré maps.

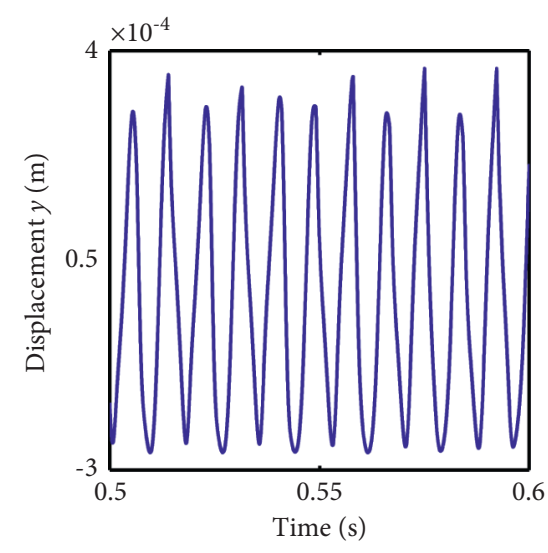

(a)

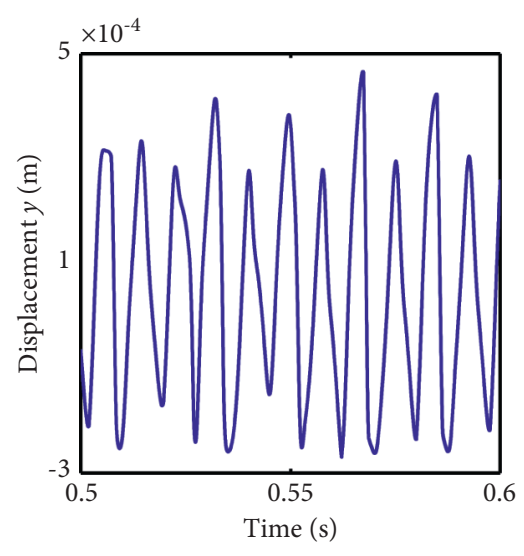

(b)

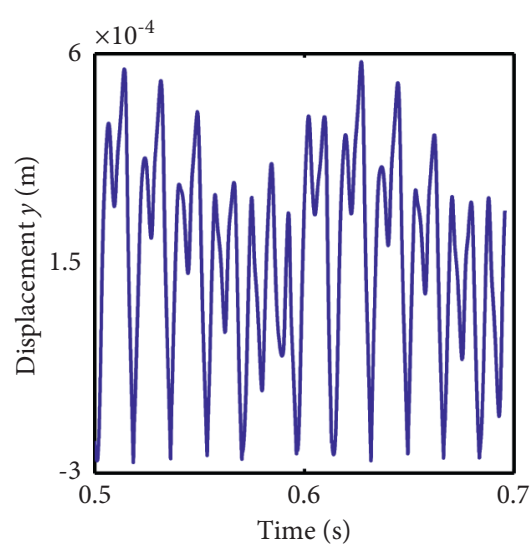

(c)

FIGURE 16: Vibration waveforms of the right journal with the change of the loose clearance. (a) $\delta=0.1 \times 10^{-3} \mathrm{~m},(\mathrm{~b}) \delta=0.27 \times 10^{-3} \mathrm{~m}$, and (c) $\delta=1 \times 10^{-3} \mathrm{~m}$.

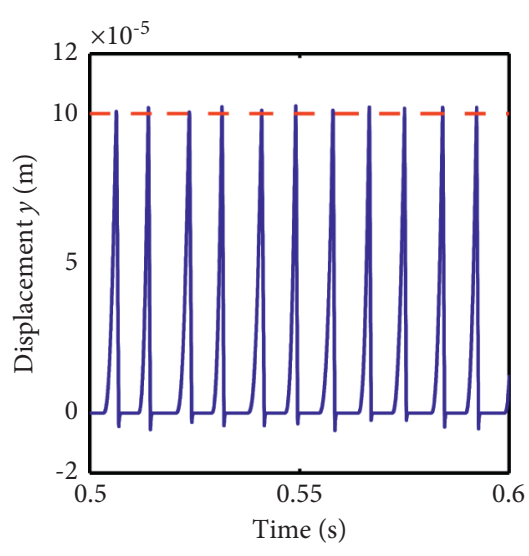

(a)

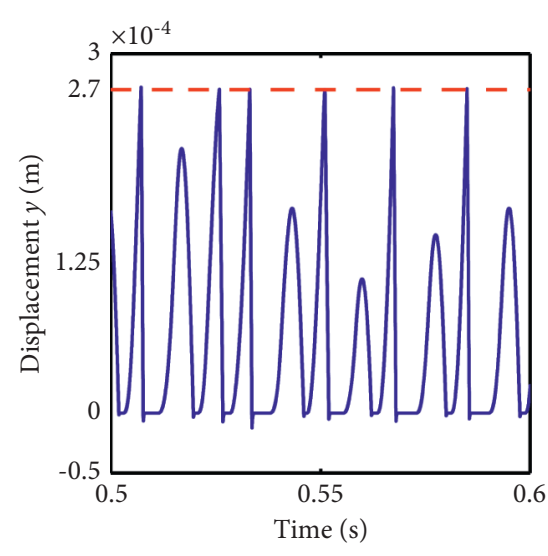

(b)

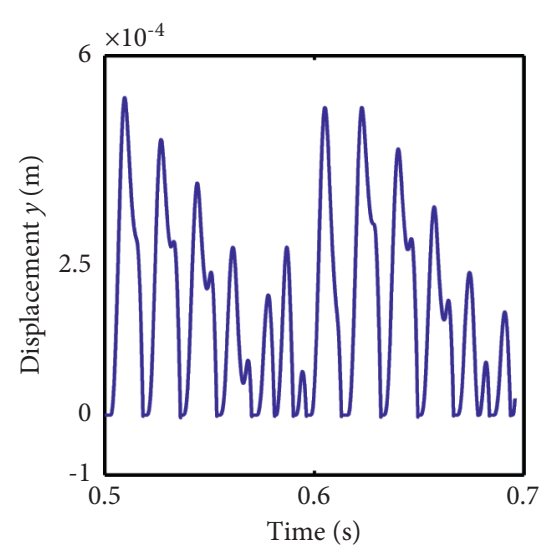

(c)

FIGURE 17: Vibration waveforms of the right bearing support with the change of the loose clearance. (a) $\delta=0.1 \times 10^{-3} \mathrm{~m},(\mathrm{~b}) \delta=0.27 \times 10^{-3} \mathrm{~m}$, and (c) $\delta=1 \times 10^{-3} \mathrm{~m}$. 


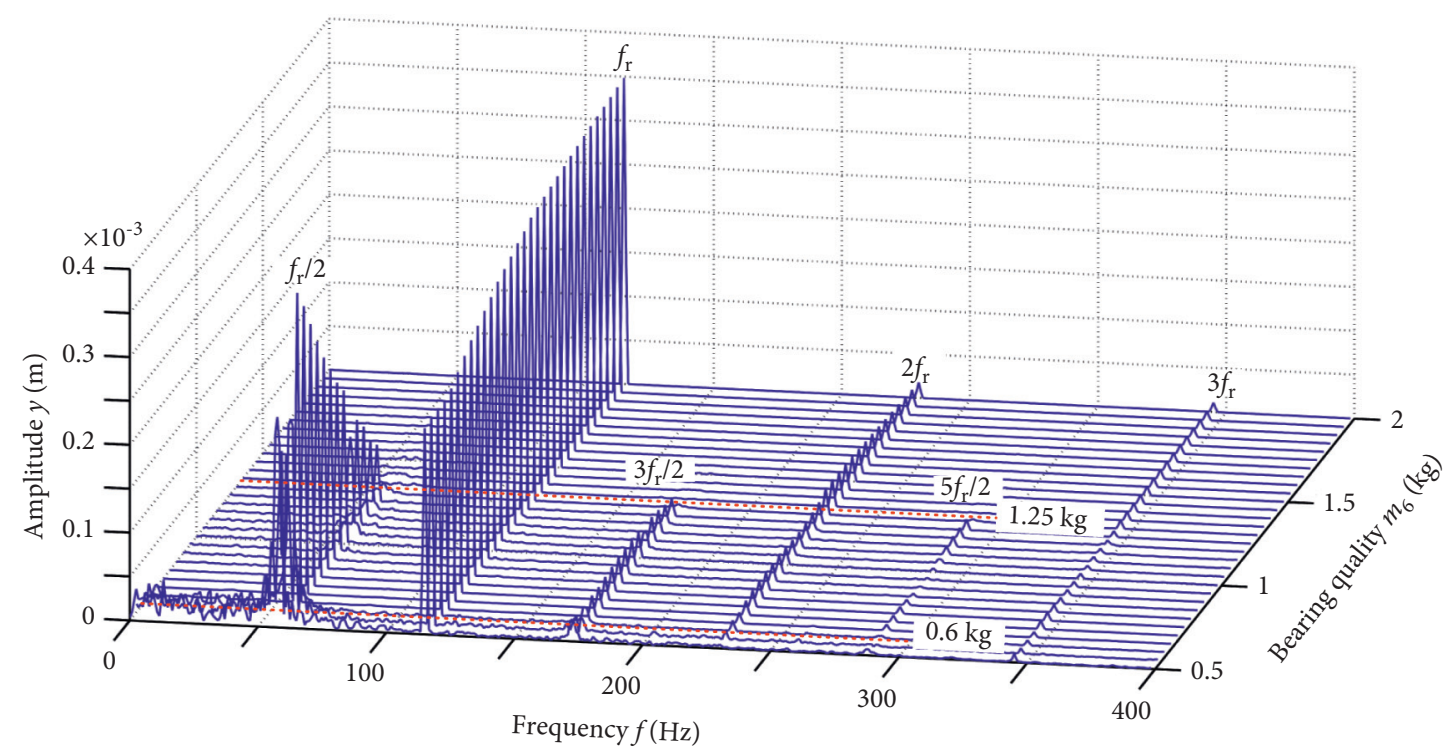

(a)

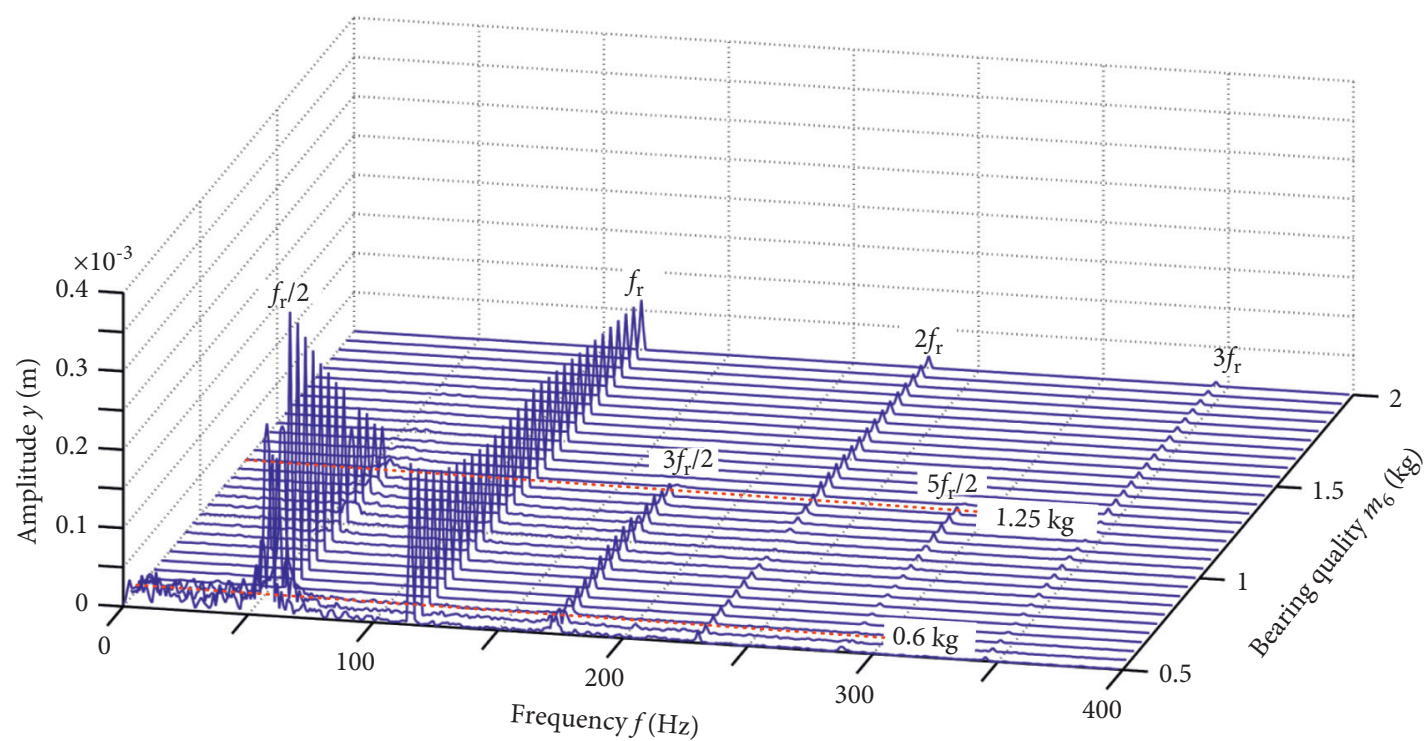

(b)

Figure 18: Spectrum cascades of the system with the change of the mass of the right bearing support. (a) Spectrum cascade of right journal. (b) Spectrum cascade of right bearing support. 


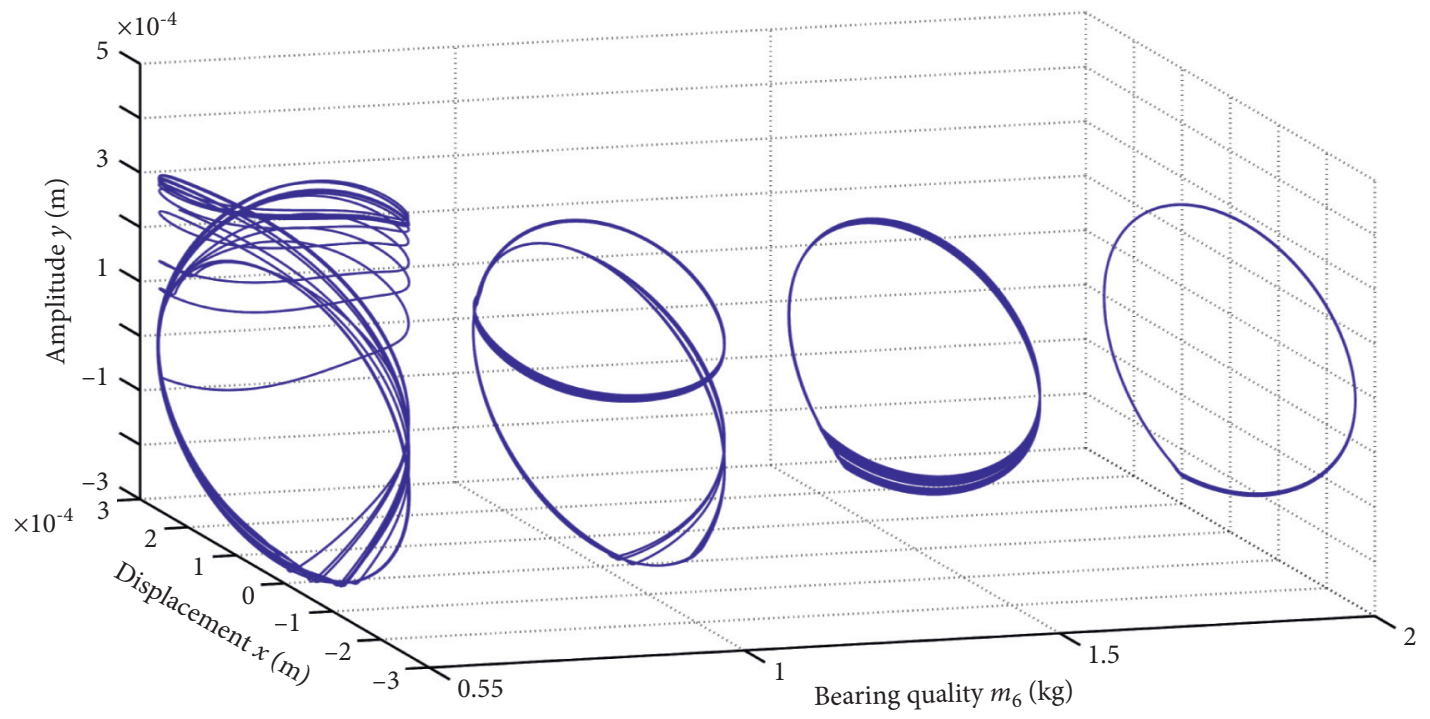

(a)

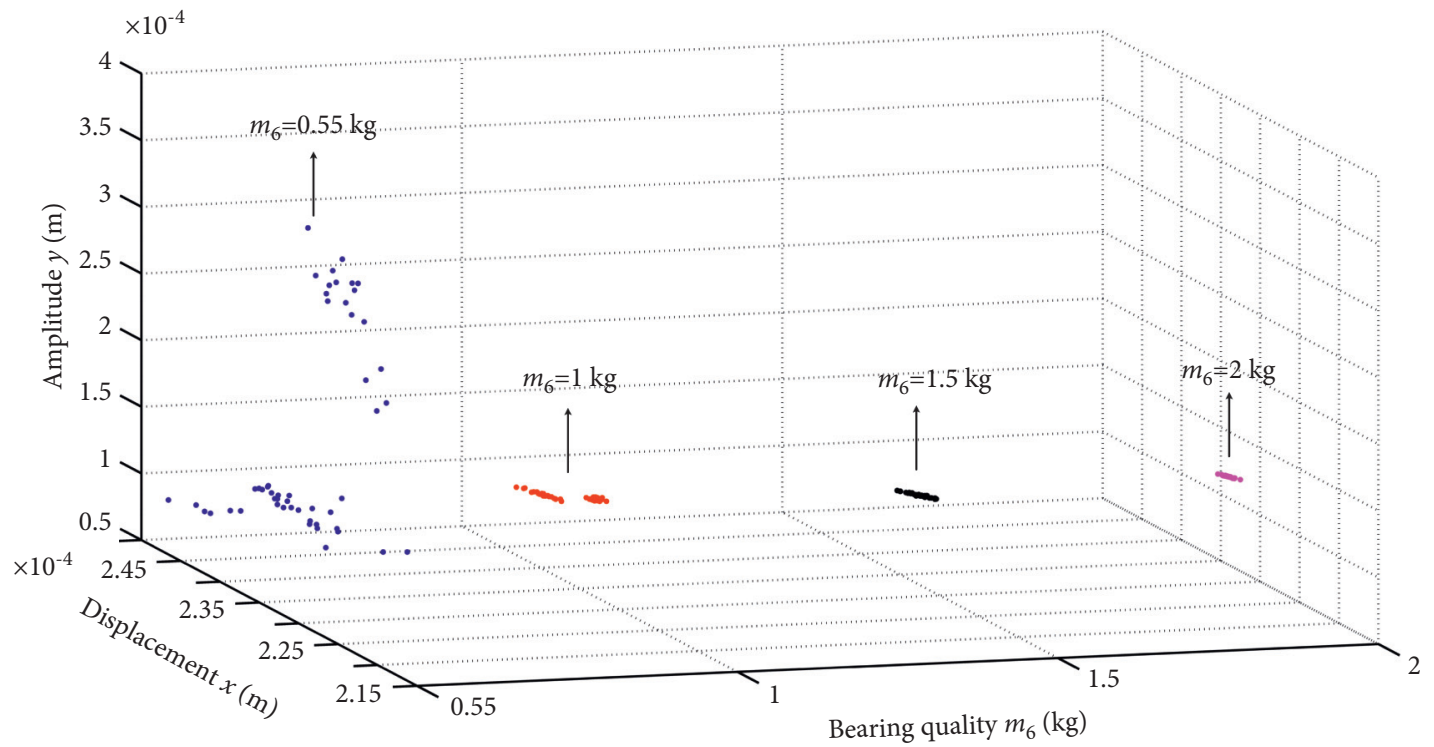

(b)

FIgURE 19: Rotor orbits and Poincaré maps of the right journal with the change of the mass of the right bearing support. (a) Rotor orbits. (b) Poincaré maps.

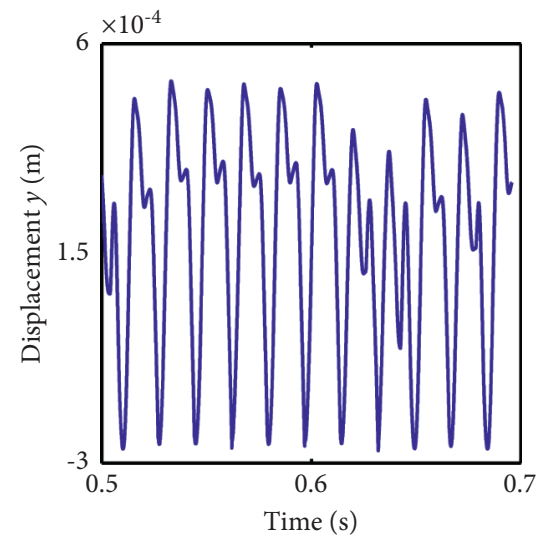

(a)

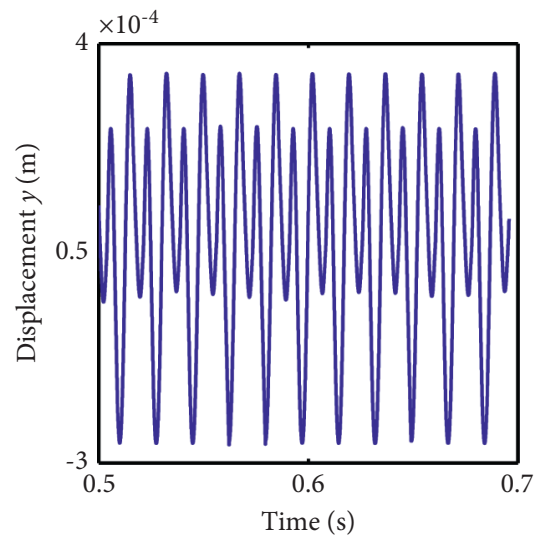

(b)

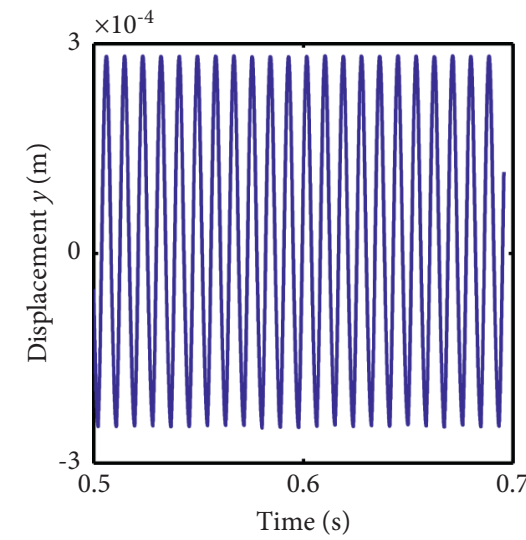

(c)

FIGURE 20: Vibration waveforms of the right journal with the change of the mass of the right bearing support. (a) $m_{6}=0.55 \mathrm{~kg},(\mathrm{~b}) m_{6}=1 \mathrm{~kg}$, and (c) $m_{6}=2 \mathrm{~kg}$. 


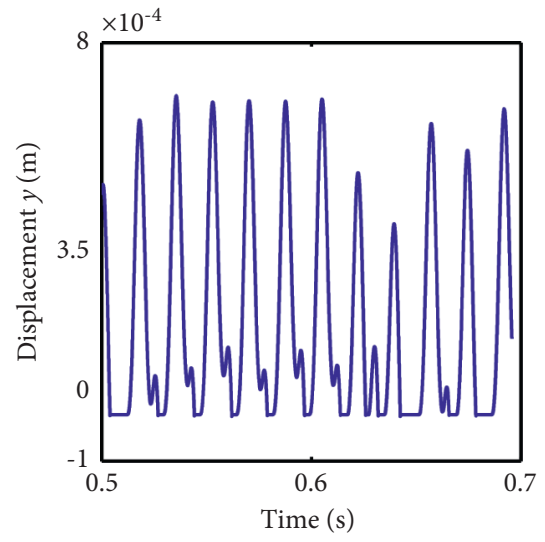

(a)

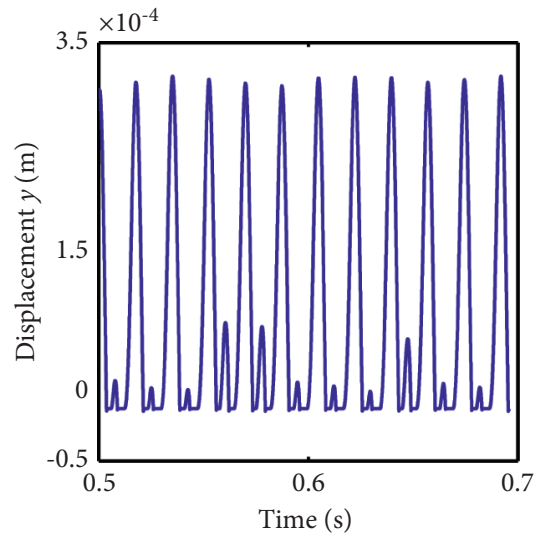

(b)

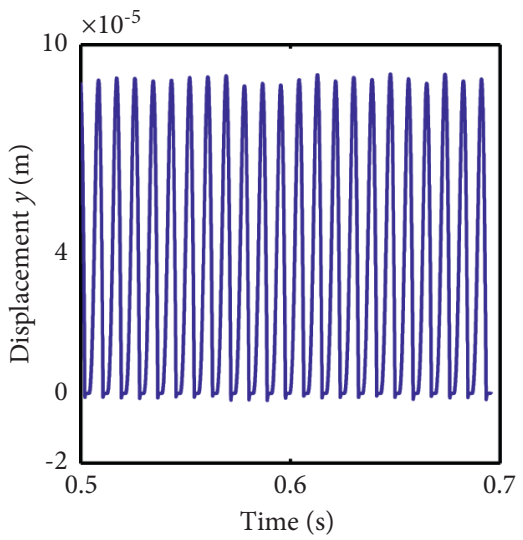

(c)

FIGURE 21: Vibration waveforms of the right bearing support with the change of the mass of the right bearing support. (a) $m_{6}=0.55 \mathrm{~kg}$, (b) $m_{6}=1 \mathrm{~kg}$, and (c) $m_{6}=2 \mathrm{~kg}$.

that as the right bearing support mass $m_{6}$ increases, the amplitude of the vibration waveforms of the journal and the support in the $y$-direction becomes smaller. This also shows that the effect of looseness is getting less and less obvious, and the larger bearing support mass can restrain the occurrence of looseness fault.

\section{Conclusions}

Based on the lumped mass model of the single-span doubledisc rotor-bearing-seal system, the dynamic characteristics of the system when the oil-film bearing support is loosened under the two working conditions of the same direction and reverse eccentricity of the two discs are studied. It mainly analyzes the influence of rotating speed, unbalance, looseness clearance, and bearing support mass on nonlinear vibration characteristics. The main conclusions obtained are as follows:

(1) The first-order oil-film oscillation locking frequency of the rotor system under different working conditions is the same, which is the first-order natural frequency of the system. Compared with Working Condition 1, Working Condition 2 is more likely to cause the bearing support to loosen. And for the rotor system studied in this paper, the looseness is more likely to occur near the second critical rotating speed.

(2) Looseness faults usually behave as fraction frequencies or continuous spectra in the spectrum. The rotor orbit will appear "cylindrical". Due to the stiffness of the unloosened end being larger, the displacement in the negative vertical direction is limited. From the vibration waveforms, the performance of the limited displacement can be clearly seen. When the displacement of the support exceeds the looseness clearance, the vibration waveforms will be limited by the foundation as well as the bolt.

(3) For the rotor system in this paper, when the looseness clearance is small, the frequency components of the system are mainly multiple frequency. When the looseness clearance is large, there are mainly fraction frequencies. The larger mass of the bearing support can restrain the looseness fault to a certain extent, but it will increase the cost. Therefore, careful consideration is needed in the design.

\section{Data Availability}

The datasets supporting the conclusions of this work are included within the article.

\section{Conflicts of Interest}

The authors declare that there are no conflicts of interest.

\section{Acknowledgments}

This work was supported by the Fundamental Research Funds for the Central Universities (Grant nos. N2003008, N2103024, N2003014, and N180708009) and the National Natural Science Foundation (Grant no. 11972112).

\section{References}

[1] Q.-S. Lu, Q.-H. Li, and E. H. Twizell, "The existence of periodic motions in rub-impact rotor systems," Journal of Sound and Vibration, vol. 264, no. 5, pp. 1127-1137, 2003.

[2] W. Qin, G. Chen, and G. Meng, "Nonlinear responses of a rub-impact overhung rotor," Chaos, Solitons \& Fractals, vol. 19, no. 5, pp. 1161-1172, 2004.

[3] Y. Liu, Y. L. Zhao, J. T. Li, H. Ma, Q. Yang, and X. X. Yan, "Application of weighted contribution rate of nonlinear output frequency response functions to rotor rub-impact," Mechanical Systems and Signal Processing, vol. 136, Article ID 106518, 2020.

[4] Y. Liu, J. T. Li, K. P. Feng, Y. L. Zhao, X. X. Yan, and H. Ma, “A novel fault diagnosis method for rotor rub-impact based on nonlinear output frequency response functions and stochastic resonance," Journal of Sound and Vibration, vol. 481, Article ID 115421, 2020. 
[5] F. Chu and Y. Tang, "Stability and nonlinear responses of a rotor-bearing system with pedestal looseness," Journal of Sound and Vibration, vol. 241, no. 5, pp. 879-893, 2001.

[6] Z. Qin, Q. Han, and F. Chu, "Bolt loosening at rotating joint interface and its influence on rotor dynamics," Engineering Failure Analysis, vol. 59, pp. 456-466, 2016.

[7] Y. Liu, Y. Zhao, J. Li, H. Lu, and H. Ma, "Feature extraction method based on NOFRFs and its application in faulty rotor system with slight misalignment," Nonlinear Dynamics, vol. 99, no. 2, pp. 1763-1777, 2020.

[8] Y. Zhao, Y. Liu, X. Yu, H. Ma, and Q. Han, "Dynamic modelling considering nonlinear factors of coupled spur gear system and its experimental research," IEEE Access, vol. 8, pp. 84971-84980, 2020.

[9] A. Muszynska and P. Goldman, "Chaotic responses of unbalanced rotor/bearing/stator systems with looseness or rubs," Chaos, Solitons \& Fractals, vol. 5, no. 9, pp. 1683-1704, 1995.

[10] X. Zhang, Q. Yan, J. Yang, J. Zhao, and Y. Shen, “An assembly tightness detection method for bolt-jointed rotor with wavelet energy entropy," Measurement, vol. 136, pp. 212-224, 2019.

[11] M. Jiang, J. Wu, X. Peng, and X. Li, "Nonlinearity measure based assessment method for pedestal looseness of bearingrotor systems," Journal of Sound and Vibration, vol. 411, pp. 232-246, 2017.

[12] S. Wei, W. Lu, and F. L. Chu, "Speed characteristics of dis$\mathrm{k}$-shaft system with rotating part looseness," Journal of Sound and Vibration, vol. 469, Article ID 115127, 2020.

[13] Y. Yang, G. Chen, H. Ouyang, Y. Yang, and D. Cao, "Nonlinear vibration mitigation of a rotor-casing system subjected to imbalance-looseness-rub coupled fault," International Journal of Non-linear Mechanics, vol. 122, Article ID 103467, 2020.

[14] Y. Yang, H. Ouyang, Y. Yang, D. Cao, and K. Wang, "Vibration analysis of a dual-rotor-bearing-double casing system with pedestal looseness and multi-stage turbine blade-casing rub," Mechanical Systems and Signal Processing, vol. 143, Article ID 106845, 2020.

[15] Y. Yang, Y. Yang, D. Cao, G. Chen, and Y. Jin, "Response evaluation of imbalance-rub-pedestal looseness coupling fault on a geometrically nonlinear rotor system," Mechanical Systems and Signal Processing, vol. 118, pp. 423-442, 2019.

[16] K. Lu, Y. Jin, Y. Chen, Q. Cao, and Z. Zhang, "Stability analysis of reduced rotor pedestal looseness fault model," Nonlinear Dynamics, vol. 82, no. 4, pp. 1611-1622, 2015.

[17] N. F. Wang, H. Z. Xu, and D. X. Jiang, "Dynamic model and fault feature research of dual-rotor system with bearing pedestal looseness," Mathematical Problems in Engineering, vol. 2016, Article ID 3817405, 18 pages, 2016.

[18] Y. G. Luo, S. H. Zhang, B. Wu, and H. Y. Hu, "Stability analysis of nonlinear stiffness rotor-bearing system with pedestal looseness fault," Applied Mechanics and Materials, vol. 483, pp. 285-288, 2013.

[19] H. Wang, X. Guan, G. Chen et al., "Characteristics analysis of rotor-rolling bearing coupled system with fit looseness fault and its verification," Journal of Mechanical Science and Technology, vol. 33, no. 1, pp. 29-40, 2019.

[20] H. Ma, X. Zhao, Y. Teng, and B. Wen, "Analysis of dynamic characteristics for a rotor system with pedestal looseness," Shock and Vibration, vol. 18, no. 1-2, pp. 13-27, 2011.

[21] W. Wang, Y. Liu, and P. Jiang, "Numerical investigation on influence of real gas properties on nonlinear behavior of labyrinth seal-rotor system," Applied Mathematics and Computation, vol. 263, pp. 12-24, 2015.
[22] S. Li, Q. Xu, and X. Zhang, "Nonlinear dynamic behaviors of a rotor-labyrinth seal system," Nonlinear Dynamics, vol. 47, no. 4, pp. 321-329, 2007.

[23] W. S. Ma, H. Huang, G. Q. Feng, Z. Chen, and R. Gordon, "Labyrinth seals diameter and length effect study on nonlinear dynamics," Procedia Engineering, vol. 99, pp. 1358-1364, 2015.

[24] E. J. Zhang, Y. H. Jiao, and Z. B. Chen, "Dynamic behavior analysis of a rotor system based on a nonlinear labyrinth-seal forces model," Journal of Computational and Nonlinear Dynamics, vol. 13, no. 10, Article ID 101002, 2018.

[25] E. J. Zhang, Y. H. Jiao, and Z. B. Chen, "Effect of radial growth on rotordynamic characteristics of labyrinth seal-rotor system," Journal of Aerospace Engineering, vol. 32, no. 4, Article ID 04019043, 2019.

[26] H. Ma, H. Li, H. Niu, R. Song, and B. Wen, "Nonlinear dynamic analysis of a rotor-bearing-seal system under two loading conditions," Journal of Sound and Vibration, vol. 332, no. 23, pp. 6128-6154, 2013.

[27] W. Li, Y. Yang, D. Sheng, and J. Chen, "A novel nonlinear model of rotor/bearing/seal system and numerical analysis," Mechanism and Machine Theory, vol. 46, no. 5, pp. 618-631, 2011.

[28] S. H. Shyu and Y. W. Chen, "Dynamic characteristics of rotorbearing system with a labyrinth seal," Key Engineering $M a$ terials, vol. 739, pp. 169-181, 2017.

[29] Y. G. Luo, P. F. Wang, H. F. Jia, and F. C. Huang, "Dynamic characteristics analysis of a seal-rotor system with rub-impact fault," Journal of Computational and Nonlinear Dynamics, vol. 16, no. 8, Article ID 081003, 2021.

[30] A. M. Zhou, L. L. Zhai, Z. C. Zhu, J. Guo, X. L. Zhang, and B. L. Cui, "Effects of transmission ratio on the nonlinear vibration characteristics of a gear-driven high-speed centrifugal pump," Shock and Vibration, vol. 2021, Article ID 6629241, 15 pages, 2021.

[31] Q. Xu, Y. Q. Luo, H. L. Yao, L. C. Zhao, and B. C. Wen, "Eliminating the fluid-induced vibration and improving the stability of the rotor/seal system using the inerter-based dynamic vibration absorber," Shock and Vibration, vol. 2019, Article ID 1746563, 9 pages, 2019.

[32] W. J. Yang, H. Q. Yuan, H. Li, and K. F. Zhang, "Dynamic analysis of flexible shaft and elastic disk rotor system based on the effect of Alford force," Shock and Vibration, vol. 2019, Article ID 3545939, 13 pages, 2019.

[33] G. Adiletta, A. R. Guido, and C. Rossi, "Chaotic motions of a rigid rotor in short journal bearings," Nonlinear Dynamics, vol. 10, no. 3, pp. 251-269, 1996.

[34] A. Muszynska, Rotordynamics, CRC Taylor \& Francis Group, Boca Raton, NJ, USA, 2005.

[35] A. Muszynska and D. E. Bently, "Frequency-swept rotating input perturbation techniques and identification of the fluid force models in rotor/bearing/seal systems and fluid handling machines," Journal of Sound and Vibration, vol. 143, no. 1, pp. 103-124, 1990.

[36] H. Ma, H. Li, X. Zhao, H. Niu, and B. Wen, "Effects of eccentric phase difference between two discs on oil-film instability in a rotor-bearing system," Mechanical Systems and Signal Processing, vol. 41, no. 1-2, pp. 526-545, 2013.

[37] Y. M. Zhang, Mechanical Vibration, Tsinghua University Press, Beijing, China, 2007.

[38] D. W. Childs, "Dynamic analysis of turbulent annular seals based on hirs' lubrication equation," Journal of Lubrication Technology, vol. 105, no. 3, pp. 429-436, 1983. 